\title{
VGLUT1 or VGLUT2 mRNA-positive neurons in spinal trigeminal nucleus provide collateral projections to both the thalamus and the parabrachial nucleus in rats
}

Chun-Kui Zhang ${ }^{1 \dagger}$, Zhi-Hong Li ${ }^{1 \dagger}$, Yu Qiao ${ }^{1,2+}$, Ting Zhang ${ }^{1}$, Ya-Cheng Lu', Tao Chen ${ }^{1}$, Yu-Lin Dong ${ }^{1}$, Yun-Qing $\mathrm{Li}^{1^{*}}$ and Jin-Lian $\mathrm{Li}^{i^{*}}$

\begin{abstract}
The trigemino-thalamic (T-T) and trigemino-parabrachial (T-P) pathways are strongly implicated in the sensory-discriminative and affective/emotional aspects of orofacial pain, respectively. These T-T and T-P projection fibers originate from the spinal trigeminal nucleus (Vsp). We previously determined that many vesicular glutamate transporter (VGLUT1 and/or VGLUT2) mRNA-positive neurons were distributed in the Vsp of the adult rat, and most of these neurons sent their axons to the thalamus or cerebellum. However, whether VGLUT1 or VGLUT2 mRNA-positive projection neurons exist that send their axons to both the thalamus and the parabrachial nucleus (PBN) has not been reported. Thus, in the present study, dual retrograde tract tracing was used in combination with fluorescence in situ hybridization (FISH) for VGLUT1 or VGLUT2 mRNA to identify the existence of VGLUT1 or VGLUT2 mRNA neurons that send collateral projections to both the thalamus and the PBN. Neurons in the Vsp that send collateral projections to both the thalamus and the PBN were mainly VGLUT2 mRNA-positive, with a proportion of $90.3 \%, 93.0 \%$ and $85.4 \%$ in the oral (Vo), interpolar ( Vi) and caudal (Vc) subnucleus of the Vsp, respectively. Moreover, approximately $34.0 \%$ of the collateral projection neurons in the Vc showed Fos immunopositivity after injection of formalin into the lip, and parts of calcitonin gene-related peptide (CGRP)-immunopositive axonal varicosities were in direct contact with the Vc collateral projection neurons. These results indicate that most collateral projection neurons in the Vsp, particularly in the Vc, which express mainly VGLUT2, may relay orofacial nociceptive information directly to the thalamus and PBN via axon collaterals.
\end{abstract}

Keywords: Vesicular glutamate transporters, Spinal trigeminal nucleus, Thalamus, Parabrachial nucleus, Collateral projection, Rat

\section{Introduction}

It is well established that the spinal trigeminal nucleus (Vsp), which contains the oral subnucleus (Vo), interpolar subnucleus $(\mathrm{Vi})$ and caudal subnucleus $(\mathrm{Vc})$, sends dense projection fibers not only to the thalamus $[1,2]$ but also the parabrachial nucleus (PBN) in the rat [3]. Previous studies have indicated that approximately $20 \%$

\footnotetext{
* Correspondence: deptanat@fmmu.edu.cn; jinlian@fmmu.edu.cn ${ }^{\dagger}$ Equal contributors

'Department of Anatomy and K.K. Leung Brain Research Centre, The Fourth Military Medical University, Xi'an, People's Republic of China

Full list of author information is available at the end of the article
}

of neurons in the Vc had collateral projections to the contralateral thalamus and ipsilateral $\mathrm{PBN}$, and more than $90 \%$ are distributed in lamina I (marginal zone) [4]. It is reported that the neurons in lamina I of the Vc respond exclusively or maximally to noxious orofacial stimuli [5].

Glutamate is the main excitatory neurotransmitter in the central nervous system. Since the successful cloning of the vesicular glutamate transporter (VGLUT) in the late 1990s [6-9], three types of VGLUTs have been identified. Two types, VGLUT1 and VGLUT2, have been considered definitive markers for glutamatergic neurons 
$[6,7,10-14]$. The different distribution patterns of the two types of VGLUTs in the central nervous system suggest that they may play different functional roles [11]. Previous reports have indicated the different distribution patterns of VGLUT1 and VGLUT2 mRNA in the principal sensory trigeminal nucleus $(\mathrm{Vp})$ and Vsp of rats [15-17], in which single $V p$ neurons that express both VGLUT1 and VGLUT2 mRNA constituted approximately $64 \%$ of glutamatergic $\mathrm{Vp}$ neurons and the majority of glutamatergic $\mathrm{T}-\mathrm{T}$ projection neurons in the Vp co-express VGLUT1 and VGLUT2 mRNA. A previous study [15] also showed that the glutamatergic T-T projection neurons in the Vsp mainly express VGLUT2, whereas trigemino-cerebellar projection neurons mainly express VGLUT1, which occurs most frequently in the $\mathrm{Vi}$, less in the $\mathrm{Vp}$, and least in the Vo. However, no single neurons that express VGLUT1 or VGLUT2 mRNA sending collateral projections to both the thalamus and PBN were reported in the Vsp, although many VGLUT1 or VGLUT2-positive axon terminals were identified in the $\mathrm{PBN}$, as previously reported [14]; moreover, whether collateral projection neurons that express VGLUT1 or VGLUT2 mRNA are involved in nociceptive signal transmission has not been reported. Thus, in the present study, we primarily examined (1) which of the two main isoforms of VGLUTs may be expressed in the T-T and T-P collateral projection neurons in each of the subdivisions of the Vsp via FISH histochemistry combined with tract tracing after microinjection of a retrograde tracer (tetramethylrhodamine dextran amine, TMR) or wheat germ agglutinin-horseradish peroxidase (WGAHRP) into the thalamic region and injection of Fluoro-Gold (FG) into the PBN region, respectively, and (2) whether the collateral projection neurons in the Vsp may be related to nociceptive signal transmission. The nociceptive neurons were confirmed by immunoreactivity for Fos, the protein product of the $c$ fos proto-oncogene, after subcutaneous injection of formalin into the upper lips $[18,19,20]$. In addition, in the $\mathrm{Vc}$, the collateral projection neurons in synaptic contact with calcitonin gene related peptide (CGRP)-like immunoreactive (-LI) axon terminals were also considered nociceptive [21]. The synaptic relationship of collateral projection neuronal profiles (FG- and WGA-HRP-labeled) to axon terminals that exhibited CGRP-LI was also examined using electron microscopy.

\section{Methods}

\section{Animals}

A total of 51 adult male rats (Sprague-Dawley) that weighed between 280 and 320 g (China SH, Xi'an, People's Republic of China) were used in the current study.
Animal use and care was approved by the Animal Care and Use Committee at the Fourth Military Medical University. Of these rats, 30 rats were used for dual retrograde tract-tracing combined with FISH histochemistry or immunofluorescence histochemistry, 15 rats were used for anterograde tract-tracing combined with immunofluorescence histochemistry, and 6 rats were used for electron microscopy.

\section{Microinjection of TMR and FG solution into the thalamus and PBN for retrograde tract-tracing}

Following an intraperitoneal injection of sodium pentobarbital ( $40 \mathrm{mg} / \mathrm{kg}$ body weight), the anaesthetized rats were placed in a stereotaxic frame

(NARISHIGE, Japan). Using a glass micropipette (internal tip diameter: $15-25 \mu \mathrm{m}$ ) that was attached to a $1 \mu \mathrm{l}$ Hamilton microsyringe, $0.6-0.8 \mu \mathrm{l}$ of $10 \%$ TMR (D-3308, 3000 MW; Molecular Probes, Eugene, OR, USA) dissolved in $0.1 \mathrm{M}$ of citrate- $\mathrm{NaOH}(\mathrm{pH} 3$. 0 ) was injected into the right thalamus, and $0.2 \mu \mathrm{l}$ of 4\% FG (80,014, Biotium, Hayward, CA, USA) dissolved in normal saline was injected into the left $\mathrm{PBN}$. After each injection, the glass micropipette was maintained in place for $15 \mathrm{~min}$. All 30 rats injected with TMR and FG were allowed to survive for 7 days. Furthermore, the rats were equally divided into two groups. While lightly anaesthetized with ethyl ether, $0.1 \mathrm{ml}$ of normal saline was injected into the upper lip ipsilateral to the FG injection site of the 15 rats in the first group, whereas the rats in the second group were subcutaneously injected with $0.1 \mathrm{ml}$ of $4 \%$ formalin dissolved in normal saline into the upper lip ipsilateral to the FG injection site. The animals subsequently survived for $2 \mathrm{~h}$ prior to euthanasia. The results of the tract tracing were obtained from 6 rats in which the tracer was injected properly into the two target areas; the remaining 24 rats were discarded because of inappropriate injection sites.

\section{FISH histochemistry combined with FG and TMR retrograde tract tracing}

The riboprobes for VGLUT1 mRNA and VGLUT2 mRNA have previously been described [22]. A cDNA fragment of VGLUT1 (nucleotides 855-1788; GenBank accession number XM_133432.2) or VGLUT2 (nucleotides 848-2044; GenBank accession number NM_080853.2) was cloned into a vector pBluescript II KS (+) (Stratagene, La Jolla, CA, USA). Using the linearized plasmids as templates, we subsequently synthesized the digoxigenin (DIG)-labeled antisense single-strand RNA probes with a DIG RNA labeling kit (Roche Diagnostic, Basel, Switzerland).

Seven days after the injection of FG and TMR, the 15 rats in the first group were re-anaesthetized intraperitoneally 
with an overdose of sodium pentobarbital $(60 \mathrm{mg} / \mathrm{kg})$; the rats were then transcardially perfused with $0.01 \mathrm{M}$ of sodium phosphate-buffered $0.9 \%(w / v)$ saline (PBS, $\mathrm{pH} 7.3$ ), followed by $500 \mathrm{ml}$ of $4 \%(\mathrm{w} / \mathrm{v})$ paraformaldehyde in $0.1 \mathrm{M}$ of phosphate buffer ( $\mathrm{PB}, \mathrm{pH}$ 7.3). After perfusion, the brains were further postfixed in $4 \%$ paraformaldehyde for 3 days at $4{ }^{\circ} \mathrm{C}$. Cryoprotected with $30 \%(\mathrm{w} / \mathrm{v})$ sucrose in $0.1 \mathrm{M}$ of $\mathrm{PB}$ for 2 days, the whole brains were serially cut into 20$\mu \mathrm{m}$-thick transverse sections using a freezing microtome (Leica CM1950; Leica, Germany).

The sections were divided into 7 series of alternate serial sections. One series of sections was directly mounted onto clean glass slides and air dried. In these sections, the location and extent of the TMR and FG injection sites, as well as the distribution of TMR- and FG-labeled neurons in the Vsp, were observed with an epifluorescence microscope (BX60; Olympus, Tokyo, Japan) under an appropriate filter for TMR (excitation 540-552 nm; emission 575-625 nm) and FG (excitation $360-370 \mathrm{~nm}$; emission $\geq 395 \mathrm{~nm}$ ).

An additional three series of the sections were used for FISH combined with immunofluorescence histochemistry. In brief, free-floating sections were treated with $2 \% \mathrm{H}_{2} \mathrm{O}_{2}$ in $0.1 \mathrm{M}$ of $\mathrm{PB}$ for $10 \mathrm{~min}$ at room temperature (RT). After rinsing with $0.1 \mathrm{M}$ of $\mathrm{PB}$, the sections were incubated in $0.3 \%$ Triton-X100 in $0.1 \mathrm{M}$ of $\mathrm{PB}$ at RT for $20 \mathrm{~min}$ and $10 \mathrm{~min}$ in acetylation solution, which consisted of $0.25 \%(\mathrm{v} / \mathrm{v})$ acetic anhydride in $0.1 \mathrm{M}$ of triethanolamine. After rinsing for $10 \mathrm{~min}$ twice, the sections were pre-hybridized for $1 \mathrm{~h}$ at $58{ }^{\circ} \mathrm{C}$ in a hybridization buffer, which contained $50 \%(\mathrm{v} / \mathrm{v})$ formamide, $5 \times$ saline sodium citrate $(\mathrm{SSC} ; 1 \times \mathrm{SSC}=0.15 \mathrm{M}$ of $\mathrm{NaCl}$ and $0.015 \mathrm{M}$ of sodium citrate, $\mathrm{pH} 7.0), 2 \%(w / v)$ blocking reagent (Roche Diagnostics), 0.1\% (w/v) Nlauroylsarcosine (NLS) and $0.1 \%(\mathrm{w} / \mathrm{v})$ sodium dodecyl sulfate (SDS). VGLUT1 or VGLUT2 riboprobes were subsequently added into the hybridization system with a final concentration of $1 \mu \mathrm{g} / \mathrm{ml}$ and hybridized at $58{ }^{\circ} \mathrm{C}$ for $20 \mathrm{~h}$. After two washes for $20 \mathrm{~min}$ at $55^{\circ} \mathrm{C}$ with wash buffer, which contained $2 \times \mathrm{SSC}, 50 \%(\mathrm{v} / \mathrm{v})$ formamide and $0.1 \%(w / v)$ NLS, the hybridized sections were incubated with $20 \mu \mathrm{g} / \mathrm{ml}$ ribonuclease A for $30 \mathrm{~min}$ at $37^{\circ} \mathrm{C}$ in a mixture of $10 \mathrm{mM}$ of Tris- $\mathrm{HCl}(\mathrm{pH} 8.0), 1 \mathrm{mM}$ of EDTA and $0.5 \mathrm{M}$ of $\mathrm{NaCl}$, followed by 2 washes for $20 \mathrm{~min}$ at $37{ }^{\circ} \mathrm{C}$ in $0.2 \times \mathrm{SSC}$ that contained $0.1 \%(w / v)$ NLS. The sections were subsequently incubated overnight at room temperature with a mixture of $0.5 \mu \mathrm{g} / \mathrm{ml}$ peroxidase-conjugated anti-digoxigenin sheep antibody (11-207-733-910; Roche Diagnostics, Basel, Switzerland), $1 \mu \mathrm{g} / \mathrm{ml}$ guinea pig anti-FG antibody (NM101, Protos Biotech Corporation, NY, USA) and $1 \mu \mathrm{g} / \mathrm{ml}$ rabbit anti-TMR antibody (A-6397, Invitrogen, Eugene, OR, USA) in $0.1 \mathrm{M}$ of Tris- $\mathrm{HCl}$ (pH 7.5)-buffered $0.9 \%$ $(\mathrm{w} / \mathrm{v})$ saline (TS 7.5$)$ that contained $1 \%$ blocking reagent
(TSB). To amplify the VGLUT1 or VGLUT2 mRNA hybridization signals, we performed the biotinylated tyramine (BT)-glucose oxidase (GO) amplification method with a reaction mixture that consisted of $1.25 \mu \mathrm{M}$ of BT, $3 \mu \mathrm{g} / \mathrm{ml} \mathrm{GO}, 2 \mathrm{mg} / \mathrm{ml} \beta$-D-glucose, and $1 \%$ bovine serum albumin (BSA) in $0.1 \mathrm{M}$ of $\mathrm{PB}$ for $30 \mathrm{~min}$. The sections were subsequently treated with a mixture of $10 \mu \mathrm{g} / \mathrm{ml}$ Fluorescein Avidin D (A-2001; Vector, Burlingame, CA, USA), $10 \mu \mathrm{g} / \mathrm{ml}$ Alexa 647-conjugated goat anti-guinea pig IgG antibody (A-21450; Invitrogen) and $10 \mu \mathrm{g} / \mathrm{ml}$ Alexa 594-conjugated donkey anti-rabbit antibody (A-21207; Invitrogen) in TSB for $4 \mathrm{~h}$.

The FISH was also performed using the sense probe (the third and fourth series of sections); however, no hybridization signals were detected in these sections.

\section{CGRP-immunoreactive axonal varicosities in the Vc were} detected in apposition to FG- and TMR-labeled neuronal profiles by triple-immunofluorescence histochemistry The fifth series of the sections through the Vc was incubated overnight with a mixture of $1 \mu \mathrm{g} / \mathrm{ml}$ guinea pig anti-FG antibody (Protos Biotech Corporation), $0.5 \mu \mathrm{g} /$ $\mathrm{ml}$ rabbit anti-TMR antibody(Invitrogen), and $1 \mu \mathrm{g} / \mathrm{ml}$ goat anti-CGRP antibody (ab36001; Abcam) in PBS$\mathrm{XCD}$. After three washes with PBS, the sections were treated with $10 \mu \mathrm{g} / \mathrm{ml}$ biotinylated donkey anti-goat IgG (AP180B, Millipore, Temecula, CA, USA). The sections were then further incubated overnight with a mixture of $10 \mu \mathrm{g} / \mathrm{ml}$ Alexa 647-conjugated goat anti-guinea pig IgG antibody (Invitrogen), $10 \mu \mathrm{g} / \mathrm{ml}$ Alexa 594-conjugated donkey anti-rabbit IgG antibody (Invitrogen), and $10 \mu \mathrm{g} /$ $\mathrm{ml}$ Fluorescein Avidin D (Vector) in PBS that contained $5 \%(v / v)$ normal donkey serum.

The sixth sections, which contained the Vsp of the rats injected with FG and TMR, were used to conduct the control experiments for immunofluorescence histochemistry, in which CGRP antibody was omitted. Under these conditions, no immunoreactivity for the omitted antibody was observed.

\section{Detection of Fos immunoreactivity in Vc neurons labeled with FG and TMR by triple-immunofluorescence histochemistry}

The last sections through the $\mathrm{Vc}$ of the rats in the first group and the sections through the $\mathrm{Vc}_{\mathrm{c}}$ from the second group injected with FG, TMR, and formalin were also processed for triple-immunofluorescence histochemistry for Fos, TMR and FG. Briefly, the sections were incubated with (1) a mixture of $1 \mu \mathrm{g} / \mathrm{ml}$ mouse anti-Fos antibody (ab 208,942, Abcam, Cambridge, MA, USA), $1 \mu \mathrm{g} / \mathrm{ml}$ guinea pig anti-FG antibody (NM-101, Protos Biotech Corporation) and 0.5 $\mu \mathrm{g} / \mathrm{ml}$ rabbit anti-TMR antibody (A-6397, Invitrogen) in PBS that contained $0.3 \%(v / v)$ Triton X-100, $0.25 \%$ 
$(w / v) \lambda$-carrageenan, and $3 \%(\mathrm{v} / \mathrm{v})$ donkey serum (PBS-XCD) overnight at room temperature; (2) $10 \mu \mathrm{g} /$ $\mathrm{ml}$ biotinylated donkey anti-mouse IgG (AP192B, Millipore, Temecula, CA, USA); and (3) a mixture of $10 \mu \mathrm{g} / \mathrm{ml}$ Alexa 647-conjugated goat anti-guinea pig IgG antibody (A-21450, Invitrogen), $10 \mu \mathrm{g} / \mathrm{ml}$ Alexa594-conjugated donkey anti-rabbit IgG antibody (A-21207, Invitrogen), and $10 \mu \mathrm{g} / \mathrm{ml}$ Fluorescein Avidin D (A-2001; Vector) in PBS that contained 3\% (v/v) normal donkey serum.

Another series of sections from the second group was used to conduct the control experiments for immunofluorescence histochemistry, in which the Fos antibody was omitted. Under these conditions, no immunoreactivity for the omitted antibody was observed.

\section{Immunofluorescence histochemistry combined with biotinylated dextran amine (BDA) anterograde tract tracing}

Anterograde tract tracing from the Vsp to the PBN regions was performed using BDA (D1956, Invitrogen) in 15 rats. In each rat, $0.2 \mu \mathrm{l}$ of $2 \%(w / v)$ BDA in distilled water was injected into the Vo (5 rats), Vi (5 rats) or Vc (5 rats). After a period of 5 days, the rats injected with BDA were sacrificed. Similar to the procedure of the FG and TMR injection experiments, the brainstem of the rats was cut into transverse sections in series, and one series of sections through Vo, Vi or Vc was directly incubated with Fluorescein Avidin D to detect the location and extent of the BDA injection site.

The sections through the PBN from the rats that had a proper BDA injection site were subsequently incubated overnight at room temperature with a mixture of $1 \mu \mathrm{g} /$ $\mathrm{ml}$ mouse anti-NeuN antibody (MAB377; Millipore, Billerica, MA) and $2 \mu \mathrm{g} / \mathrm{ml}$ guinea pig anti-VGLUT2 $(135,404$, Synaptic Systems, Goettingen, German) in PBS that contained PBS-XCD, followed by $6 \mathrm{~h}$ at RT with a mixture of $5 \mu \mathrm{g} / \mathrm{ml}$ Fluorescein Avidin D (Vector), $5 \mu \mathrm{g}$ / $\mathrm{ml}$ Alexa 594-conjugated goat anti-guinea pig IgG antibody (A-11076, Invitrogen) and $5 \mu \mathrm{g} / \mathrm{ml}$ Alexa 647conjugated donkey anti-mouse IgG antibody (A-31571, Invitrogen).

\section{Confocal laser scanning microscopy for the immunofluorescence stained sections}

After incubation, all immunofluorescence stained sections were observed under a confocal laser scanning microscope (FV1000; Olympus, Tokyo, Japan) with appropriate laser beams and filter sets for fluorescein (excitation $488 \mathrm{~nm}$, emission 510-530 nm), TMR and Alexa 594 (excitation $543 \mathrm{~nm}$, emission 590-615 nm) or Alexa 647 (excitation $633 \mathrm{~nm}$, emission $650 \mathrm{~nm}$ ). We captured the digital images with an FV10-ASW 1.6 from Olympus; following modifications (15-20\% contrast enhancement) in Photoshop CS4 (Adobe Systems, San Jose, CA), these images were saved as TIFF files.

\section{Cell counting and statistics}

In the 3 rats in which the FG injection into the PBN and TMR injection into the thalamus were successful, the TMR- and FG-labeled cell bodies of neurons that expressed VGLUT1 or VGLUT2 mRNA were identified by FISH combined with retrograde tract tracing. For these counts, in each rat, we selected 15 sections that covered the whole rostral-caudal axis of the Vsp, $5 \mathrm{sec}$ tions of the Vo, 5 sections of the Vi and 5 sections of the Vc. In the other 3 rats, after the TMR and FG were administered and the formalin was subcutaneously injected into the upper lip ipsilateral to the FG injection site, the TMR- or FG-labeled cell bodies of neurons that expressed Fos immunoreactivity were identified by immunohistochemistry combined with retrograde tract tracing. For these counts, in each rat, 10 sections that covered the whole rostral-caudal axis of the Vc were selected. The target areas (Vo, Vi or Vc) were subsequently photographed with a confocal laser microscope under a $10 \times$ objective, and the number of neurons doublelabeled with TMR/FG, TMR/VGLUT1 mRNA, TMR/ VGLUT2 mRNA, FG/VGLUT1 mRNA, or FG/VGLUT2 mRNA, and the neurons triple-labeled with TMR/FG/ VGLUT1, TMR/FG/VGLUT2 or TMR/FG/Fos were counted based on these photographs. In all experiments, only cells with a clear nucleus were counted.

For statistics, the numbers of the counted cells of each rat were initially summed and then averaged among the three rats. All data are presented as the mean \pm standard deviation (SD). Student's $t$ test was used to determine whether the number of Fos immuno-reactive cells in the $V_{c}$ of the rats after formalin injection was significantly different from that in the rats injected with normal saline. For cell counting in the Vc, the identification of each lamina of the Vc referred to the rat brain atlas by Paxinos [23] and the book "The Rat Nervous System" by Paxinos [24]. The layers consist of a marginal layer (lamina I) and substantia gelatinosa (lamina II), which together comprise the superficial laminae, and a deeper magnocellular layer (laminae III and IV; a separate lamina III is not obvious in the rat; however, it is typically included in the magnocellular layer).

\section{Triple immune-electron microscopy showed CGRP-} immunoreactive terminals in synaptic contact with WGAHRP- and FG-labeled neuronal profiles in Vc

Six rats were injected with WGA-HRP and FG for electron microscopy. In each rat, $0.2 \mu$ l of FG was injected by pressure into the left PBN as previously described. After 4 days, the rats were re-anaesthetized with sodium 
pentobarbital ( $40 \mathrm{mg} / \mathrm{kg}$ body weight) and stereotaxically injected with $0.6 \mu \mathrm{l}$ of $1 \%$ WGA-HRP (PL-1026, Vector) into the right thalamus of the FG injected rats. The procedures for the stereotaxic microinjection of the WGAHRP solution were the same as described for FG. After the injection of WGA-HRP, the rats were allowed to survive for 3 days.

The rats were deeply anaesthetized and transcardially perfused with $200 \mathrm{ml}$ of $4 \%(w / v)$ paraformaldehyde, 0 . $1 \%(\mathrm{w} / \mathrm{v})$ glutaraldehyde, and $15 \%(\mathrm{v} / \mathrm{v})$ saturated picric acid in $0.1 \mathrm{M}$ of $\mathrm{PB}$. The brainstems were serially cut into $50-\mu \mathrm{m}$-thick transverse sections with a Vibratome (Microslicer DTM-1000; Dosaka EM, Kyoto, Japan). The staining of WGA-HRP was processed using tetramethylbenzidine (TMB) with sodium tungstate as a stabilizer [25], and the WGA-HRP reaction products were further intensified with $\mathrm{DAB} /$ cobalt $/ \mathrm{H}_{2} \mathrm{O}_{2}$ solution. The sections that contained the injection sites were subsequently mounted onto glass slides for the conformation of the injection site. The sections through the $\mathrm{Vc}$ from 3 animals with both WGA-HRP and FG injection sites restrained in the target area were selected and incubated in a mixture of $25 \%(w / v)$ sucrose and $10 \%(v / v)$ glycerol in $0.05 \mathrm{M}$ of $\mathrm{PB}$ for $1 \mathrm{~h}$. The sections were transiently frozen and thawed with liquid nitrogen. Following incubation at room temperature with $0.05 \mathrm{M}$ of Tris- $\mathrm{HCl}-$ buffered saline (TBS; pH 7.4) that contained $20 \%(\mathrm{v} / \mathrm{v})$ normal donkey serum for $1 \mathrm{~h}$, the sections were processed for double immunolabeling of FG and CGRP. In brief, the sections were incubated at room temperature overnight with $1 \mu \mathrm{g} / \mathrm{ml}$ rabbit anti-FG antibody (A153-I, Millipore) and $1 \mu \mathrm{g} / \mathrm{ml}$ mouse anti-CGRP antibody (ab81887, Abcam) in TBS that contained 2\% (v/v) normal donkey serum (TBS-D). After rinsing with TBS, the sections were incubated in TBS-D with $10 \mu \mathrm{g} / \mathrm{ml} 1.4-\mathrm{nm}$ gold-particle-conjugated goat anti-rabbit IgG antibody (2004; Nanoprobes, Stony Brook, NY, USA) and $10 \mu \mathrm{g} /$ $\mathrm{ml}$ biotin-conjugated donkey anti-mouse IgG antibody (Millipore) overnight. The sections were subsequently treated with $1 \%(w / v)$ glutaraldehyde in $0.1 \mathrm{M}$ of $\mathrm{PB}$ (pH 7.4) for $10 \mathrm{~min}$ and rinsed with distilled water. An HQ Silver Kit (2012; Nanoprobes) was subsequently employed to perform silver enhancement. The sections were then incubated with a 1:50-diluted Elite $\mathrm{ABC}$ Kit (PK-2101, Vector) in $0.05 \mathrm{M}$ of TBS for $6 \mathrm{~h}$ and further treated with $0.02 \%(\mathrm{w} / \mathrm{v})$ 3,3-diaminobenzidine tetrahydrochloride (DAB; D5637, Sigma, St. Louis, MO, USA) and $0.3 \%(v / v) \mathrm{H}_{2} \mathrm{O}_{2}$ in $0.05 \mathrm{M}$ of Tris- $\mathrm{HCl}(\mathrm{pH}$ 7.6) for $30 \mathrm{~min}$. The sections were subsequently incubated in $1 \%$ $(\mathrm{w} / \mathrm{v}) \mathrm{OsO} 4$ in $0.1 \mathrm{M}$ of $\mathrm{PB}(\mathrm{pH} 7.4)$ for $35 \mathrm{~min}$ and counterstained in $70 \%$ ethanol that contained $1 \%(\mathrm{w} / \mathrm{v})$ uranyl acetate for $1 \mathrm{~h}$. With dehydration, the sections were mounted onto silicon-coated glass slides, and 1 was embedded in epoxy resin (Durcupan; Fluka, Buchs,
Switzerland). Once the resin polymerized, section fragments that contained the superficial layer of the Vc were removed from the resin. The selected tissue fragments were further cut into 60-nm-thick sections using an ultramicrotome (Reichert-Nissei Ultracut S; Leica). The ultrathin sections were then mounted onto single-slot grids coated with pioloform membranes and detected with a JEM-1400 electron microscope (JEM, Tokyo, Japan).

\section{Results}

Both a TMR injection into the thalamus and an FG injection into the PBN were performed in 30 rats. In the sites of the TMR or FG injections into the thalamus or $\mathrm{PBN}$, a dense core of the tracer was surrounded by a diffuse halo of the same. The brightest injection areas were considered to represent the injection site. When a TMR injection site was confined within the targeted area in the VPM and Po and their immediate vicinities, the TMR injection into the thalamus was considered successful. When the lateral and medial parabrachial nuclei (LPB and MPB), including the Kölliker-Fuse nucleus, were involved in an injection site, the FG injection into the PBN region was considered successful. Thus, 6 of the 30 rats were considered to be successfully injected, as the TMR and FG injection sites both involved the target area (Figs. 1, 2 and 6). Although the location and extent of the injection sites in these 3 rats (R4, R7, and R13 in TMR and FG; R18, R25, and R29 in TMR, FG, Fos) were variable, the patterns of retrograde labeling in the Vsp were relatively similar.

\section{Dual retrograde tract tracing combined with FISH histochemistry for VGLUT1 or VGLUT2 mRNA}

To examine whether Vsp neurons that express VGLUT1 or VGLUT2 mRNA may send their axon collaterals to the contralateral thalamus and ipsilateral $\mathrm{PBN}$, retrograde tract tracing combined with FISH histochemistry for VGLUT1 or VGLUT2 mRNA was performed after TMR injection into the right thalamus and FG injection into the left PBN in R4, R7 and R13 (Figs. 1 and 2). Using confocal laser scanning microscopic detection, many TMR- or FG-labeled neurons were observed in the left Vsp (ipsilateral to the FG injection into the PBN; contralateral to the TMR injection into the thalamus), whereas only a small number were observed on the right side. Thus, all observations were focused on the left Vsp.

In general, the results indicated that relatively more TMR-labeled neurons were observed in the Vi (Figs. 3b and $4 \mathrm{~b}$ ), and fewer neurons were scattered within the Vo (Figs. 3a and 4a) and Vc (Figs. 3c and 4c). FG-labeled neurons were distributed in the Vo with slight dominance at the caudal levels (Figs. 3a and 4a), whereas the ventral and dorsal parts at the rostro-caudal axis of 

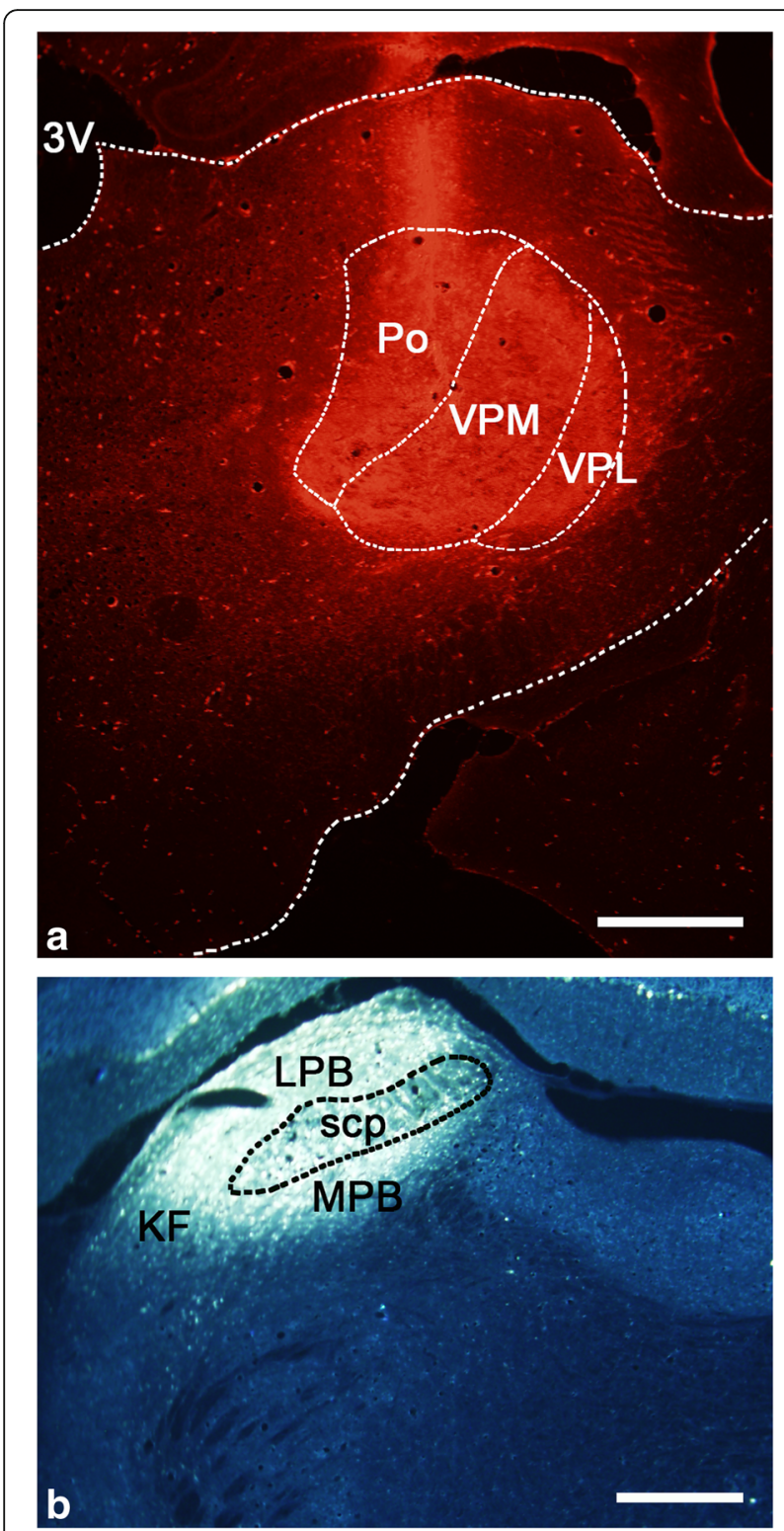

Fig. 1 Photomicrographs of a section through the middle level of a TMR injection site in the right side of the thalamus, involving the VPM and Po (a), and an FG injection site in the left side of the PBN (b) in R7. Scale bar $500 \mu \mathrm{m}(\mathbf{a}) ; 300 \mu \mathrm{m}$ (b)

the $\mathrm{Vi}$ showed slight dominance at the rostral levels (Figs. $3 \mathrm{~b}$ and $4 \mathrm{~b}$ ). In the Vc, most of the TMR-labeled neurons were located in the superficial layer (Figs. 3c and $4 \mathrm{c}$ ). Similar to the TMR-labeled neurons, the FGlabeled neurons in the Vc were mainly distributed in the superficial layer (Fig. 3c, c2, c4; Fig. 4c, c2, c4). There was a substantial number of neuronal cells with VGLUT2 mRNA signals distributed throughout the Vsp (Fig. 3c). In contrast, neurons with VGLUT1 mRNA signals were also abundant in the Vi (Fig. 4b, b3, b4), whereas only a small number were scattered in the Vo (Fig. 4a, a3, a4) and Vc (Fig. 4c, c3, c4).
Moreover, the VGLUT1 mRNA-positive neurons were mainly distributed in the deep layer of the Vc (compare Fig. 4c with Fig. 3c).

Furthermore, cell counts were performed in the Vsp of the three rats with images obtained via confocal laser scanning microscopy (Tables 1 and 2). TMR/FG double-labeled neurons in the Vo, Vi and $\mathrm{Vc}$ accounted for $(90.5 \pm 1.8) \%,(92.5 \pm 1.9) \%$ and $(49.6 \pm 1.0) \%$ of the TMR-labeled cells, respectively, and $(53.5 \pm 2.5) \%,(73.6 \pm 1.2) \%$ and $(43.7 \pm 1.9) \%$ of the FG-labeled cells, respectively (Table 1). Overall, $(88.2 \pm 2.5) \%,(92.0 \pm 5.3) \%$ and $(64.5 \pm 1.0) \%$ of the TMR retrograde-labeled neurons and $(6.0 \pm 0.2)$ $\%,(22.2 \pm 1.6) \%$ and $(0.7 \pm 0.1) \%$ of the VGLUT2 mRNA positive cells exhibited double labeling of TMR and VGLUT2 mRNA in the Vo, Vi and Vc, respectively (Table 1). Furthermore, $(83.9 \pm 1.6) \%$, $(96.6 \pm 1.1) \%$ and $(90.7 \pm 2.9) \%$ of the FG retrogradely labeled neurons and $(9.7 \pm 0.2) \%$, $(29.2 \pm 0.7)$ $\%$ and $(1.1 \pm 0.1) \%$ of the VGLUT2 mRNA-positive cells exhibited double labeling for both FG and VGLUT2 mRNA (Table 1). TMR/FG/VGLUT2

triple-labeled neurons accounted for $(81.7 \pm 3.5) \%$, $(86.0 \pm 0.7) \%$, and $(42.4 \pm 0.9) \%$ of the TMR-labeled neurons, $(48.3 \pm 1.7) \%,(68.4 \pm 0.3) \%$ and $(37.3 \pm 1.6)$ $\%$ of the FG-labeled neurons, $(5.6 \pm 0.1) \%$, $(20.7 \pm 0.2) \%$ and $(0.4 \pm 0.0) \%$ of the VGLUT2 mRNA positive cells, and $(90.3 \pm 4.1) \%,(93.0 \pm 1.2) \%$ and $(85.4 \pm 0.7) \%$ of the TMR/FG double labeled neurons in the Vo, Vi and Vc (Table 1).

Moreover, $(19.1 \pm 2.5) \%,(0.5 \pm 0.4) \%$ and $(4.5 \pm 2.1)$ $\%$ of the TMR retrogradely labeled neurons and (12.6 $\pm 1.9) \%, \quad(0.2 \pm 0.1) \quad \%$ and $(1.2 \pm 0.6) \%$ of the VGLUT1 mRNA positive cells exhibited dual labeling of TMR/VGLUT1 mRNA in the Vo, Vi and Vc,

respectively (Table 2$)$. Overall, $(14.1 \pm 2.4) \%$, $(1.3 \pm 0$. $7) \%$ and $(4.1 \pm 2.0) \%$ of the FG retrogradely labeled neurons and $(16.1 \pm 2.6) \%,(0.5 \pm 0.2) \%$ and $(1.2 \pm 0$. 6) $\%$ of the VGLUT1 mRNA-positive cells were double labeled for both FG and VGLUT1 mRNA (Table 2). TMR/FG/VGLUT1 triple-labeled neurons comprised $(26.8 \pm 3.0) \%$ and $(1.0 \pm 0.7) \%$ of the MRlabeled neurons, $(15.5 \pm 2.2) \%$ and $(0.9 \pm 0.6) \%$ of the FG-labeled neurons, $(17.7 \pm 2.4) \%$ and $(0.3 \pm 0.2) \%$ of the VGLUT1 mRNA positive cells, and $(29.9 \pm 3.0) \%$ and $(2.0 \pm 1.4) \%$ of the FG/TMR double-labeled neurons in the Vo and Vc, respectively (Table 2). In the Vi, no TMR/ FG/VGLUT1 triple-labeled neurons were identified; however, some neurons showed TMR/FG, TMR/VGLUT1 or FG/VGLUT1 double-labeling (Table 2).

Thus, these data indicated that the vast majority of the Vo, Vi and Vc neurons that projected both ipsilaterally to the PBN and contralaterally to the thalamus by way of axon collaterals were VGLUT2 mRNA- 


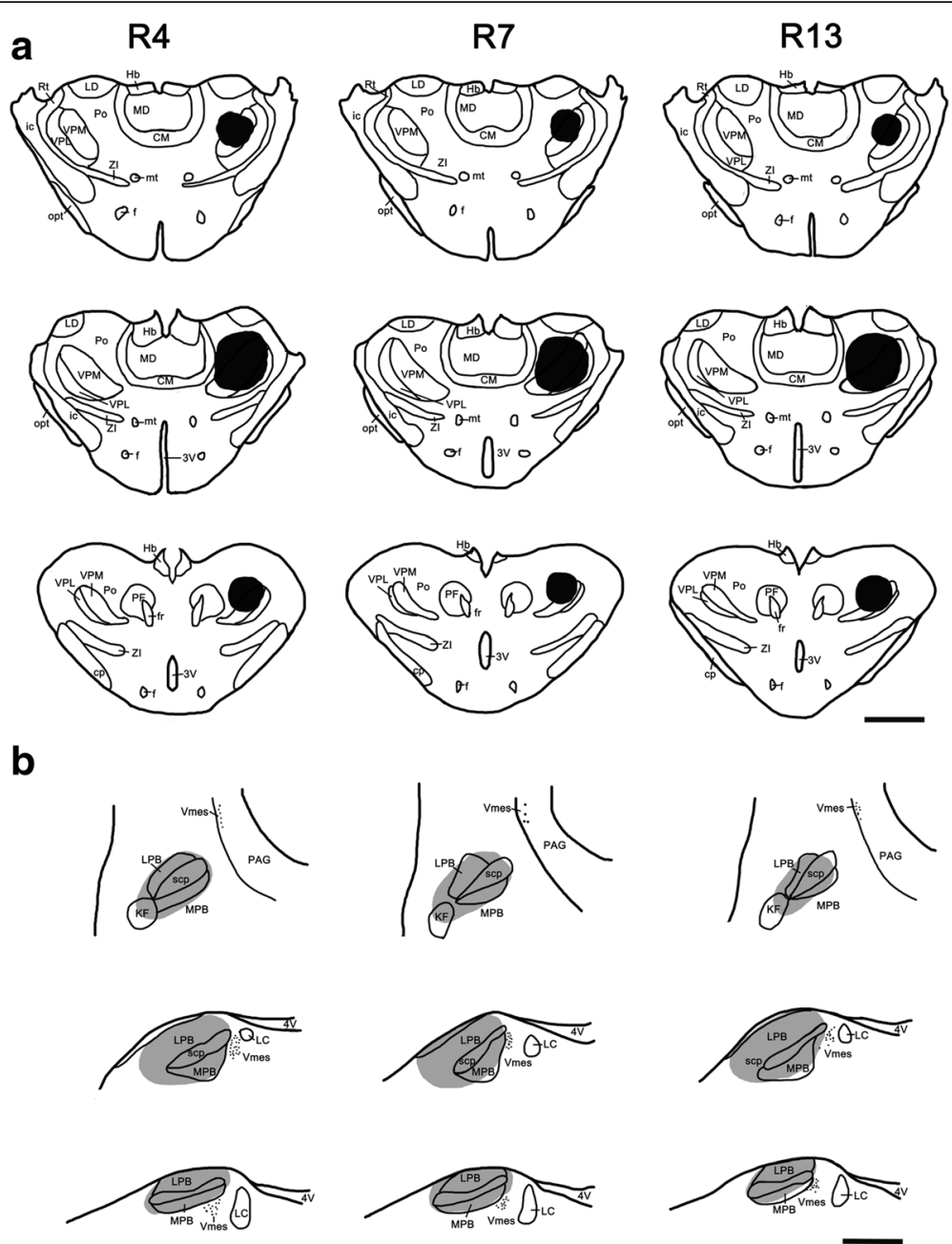

Fig. 2 Projection drawings indicate the sites of TMR injection into the thalamus and FG injection into the PBN in three rats (R4, R7, and R13). a Three different sections from rostral to caudal of the thalamus show the TMR injection sites confined in the VPM, the Po and their vicinities. b FG was injected into the left PBN, with the densest core (blackened areas) covering parts throughout the PBN and the KF. Scale bar 2 mm $(\mathbf{a}) ; 1 \mathrm{~mm}(\mathbf{b})$

positive (Table 1), whereas a limited number expressed VGLUT1 mRNA (Table 2).

\section{Immunofluorescence histochemistry combined with} anterograde tract-tracing after BDA injection into the Vo, vi and Vc

Anterograde tract-tracing experiments combined with immunofluorescence histochemistry for VGLUT2-LI were performed in 15 rats after unilateral injection of BDA into the Vo, Vi and Vc (Fig. 5a-c); the BDA injection sites were also immunostained with NeuN. The site of the BDA injection in the rats covered nearly the complete extent of the Vo (Fig. 5a), Vi (Fig. 5b) and Vc (Fig. 5c). In these experiments, the distribution of BDAlabeled axons and terminals in the PBN was very similar (Fig. 5a1, b1, c1). Anterograde labeling was present bilaterally in the PBN and KF, with a clear ipsilateral predominance. The highest density of BDA-labeled axon terminals was present caudally in the KF and in the ventral portion of the LPB (Fig. 5a1, b1, c1). The sections stained by triple-immunofluorescence labeling for VGLUT2/NeuN/BDA (for the rats injected with BDA to the $\mathrm{Vo}, \mathrm{Vi}$ and $\mathrm{Vc}$ ) were subsequently examined under a confocal laser scanning microscope, and the results showed that many BDA-labeled small granules in the PBN and KF showed VGLUT2 immunoreactivity (Fig. $5 \mathrm{a} 2, \mathrm{~b} 2, \mathrm{c} 2$ ).

Immunoreactivities for Fos in the Vc after subcutaneous injection of formalin into the rat upper lip

To examine whether the Vc collateral projection neurons previously identified may be involved in the transmission of orofacial nociceptive information, retrograde tract tracing combined with Fos immunohistochemistry was 


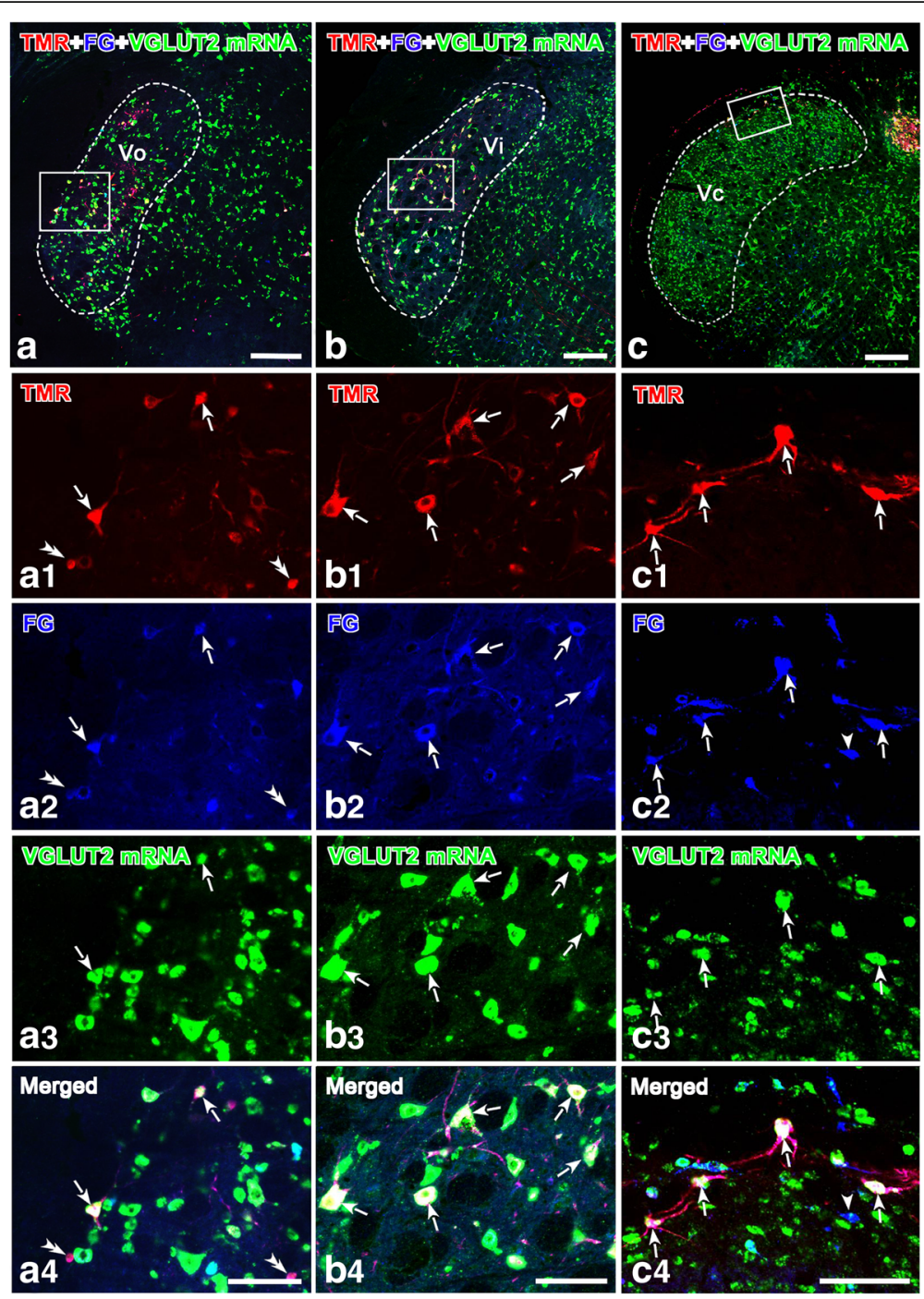

Fig. 3 Collateral projection neurons to both the thalamus and the PBN labeled with hybridization signals for VGLUT2 mRNA in the Vo (a, a1-a4), Vi (b b1-b4) and Vc (c, c1-c4). Some neurons are retrogradely labeled with TMR and FG. Immunoreactivity for TMR is visualized with Alexa 594 (red), and immunoreactivity for FG is visualized with Alexa 647 (blue), whereas the VGLUT2 mRNA hybridization signals are shown with fluorescein (green). Images (a1-a4, b1-b4 And c1-c4) are the magnified images of the framed areas in ( $\mathbf{a}, \mathbf{b}$ and $\mathbf{c}$ ), respectively. The arrows in (a1-c4) indicate the cell bodies triply labeled with TMR/FGNGLUT2 mRNA signals (white); the double arrowheads in a1-c4 indicate the cell bodies dually labeled with TMR and FG (purple red); the single arrowheads in (a1-c4) point to cell bodies singly labeled with FG (blue). Scale bar 300 um (a-c); $100 \mu \mathrm{m}$ (a1-c4)

performed after TMR injection into the right thalamus and FG injection into the left PBN. Similar to the first group that was injected with normal saline in the upper lip, 3 rats in the second group were also considered successful, as both of the injection sites of FG and TMR were restricted in the PBN and thalamus, respectively (R18, R25, and R29, Fig. 6). The results showed that FosLI cell bodies in the superficial layer (laminar I and laminar II) of the left Vc in the rats injected with formalin (Fig. 7e-h) significantly increased (Fig. 8a, $P<0.001,30$ sections from 3 rats) compared with those in the rats injected with normal saline (Fig. 7a-d). Moreover, the percentage of FG/TMR dual-labeled neurons in the superficial layer that showed Fos LI also significantly increased $[(24.3 \pm 2.8) \%$ to $(42.8 \pm 3.8) \%, P<0.001$, 30 sections from 3 rats] with the formalin injection (Fig. 8b). In detail, for the animals injected with formalin, $(29.3 \pm 0.4) \%$ and $(24.5 \pm 1.7) \%$ of the Fos labeled Vc neurons were identified in laminae I and II, respectively, and $(46.2 \pm 0.5) \%$ was distributed in lamina III (Table 3 ). TMR/FG double-labeled neurons were mainly distributed in lamina I of the Vc, with $(64.0 \pm 4.4) \%$ of the total double-labeled neurons in lamina I and only $(15.5 \pm 6.5) \%$ and $(22.1 \pm 2.9) \%$ scattered in laminae II and III, respectively. In addition, TMR/FG/Fos triple-labeled neurons were mainly distributed in lamina $\mathrm{I}$ of the $\mathrm{Vc}$ and 


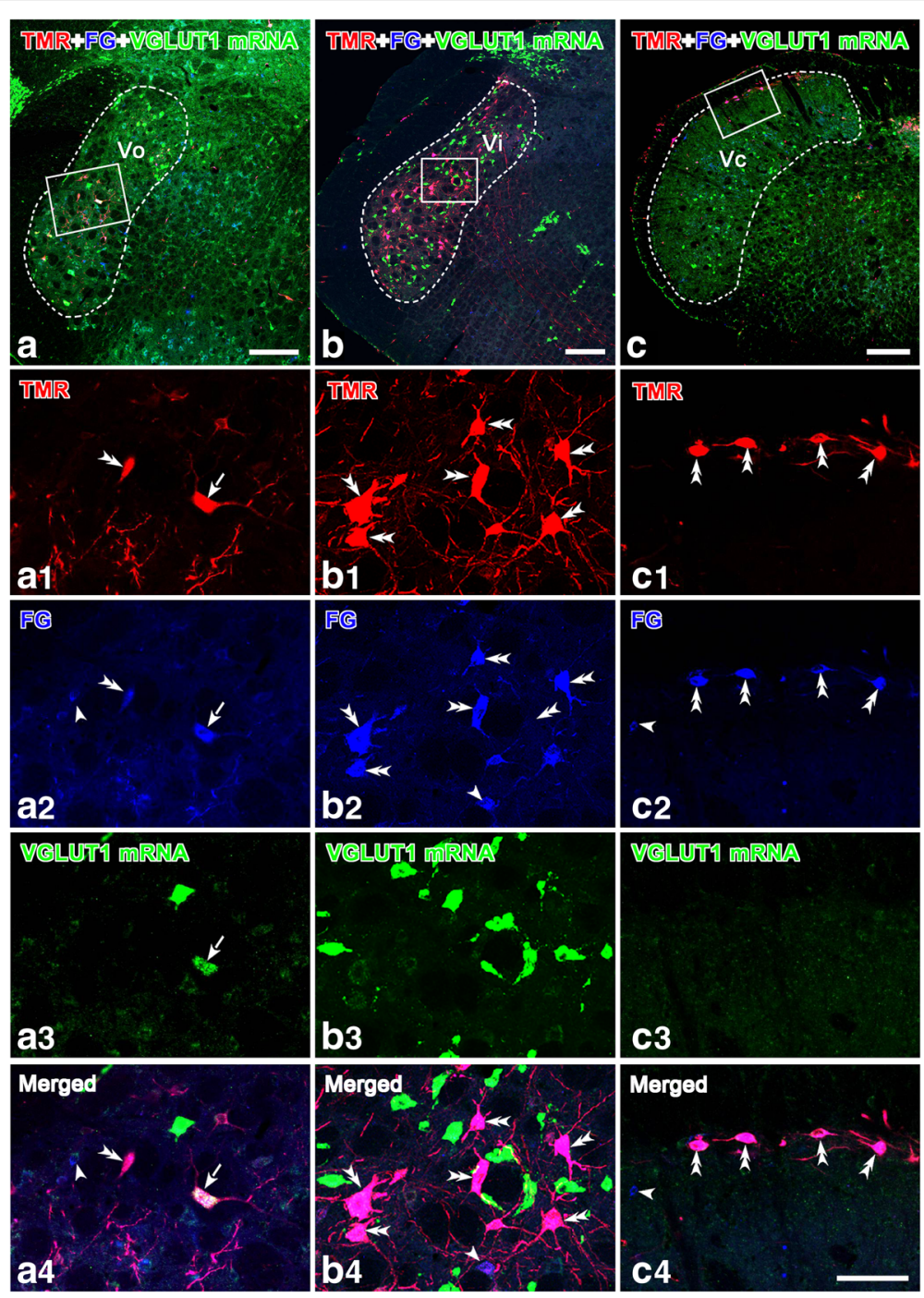

Fig. 4 Collateral projection neurons to both the thalamus and the PBN labeled with hybridization signals for VGLUT1 mRNA in the Vo (a, a1-a4), Vi (b, b1-b4) and Vc (c, c1-c4). Some neurons are retrogradely labeled with TMR and FG. Immunoreactivity for TMR is visualized with Alexa 594 (red), and immunoreactivity for FG is visualized with Alexa 647 (blue), whereas the VGLUT1 mRNA hybridization signals are shown with fluorescein (green). Images (a1-a4), (b1-b4) and (c1-c4) are the magnified images of the framed areas in (a), (b) and (c), respectively. The arrows in (a1-a4) indicate the cell bodies triply labeled with TMR/FG/NGLUT1 mRNA signals (white); the double arrowheads in (a1-c4) indicate the cell bodies dually labeled with TMR and FG (purple red); the single arrowheads in (a1-c4) point to cell bodies singly labeled with FG (blue). Scale bar 300 um (a-c); 100 um (a1-c4)

accounted for $(77.8 \pm 2.1) \%$ of the total triple-labeled neurons in the Vc (Table 3).

CGRP-like immunopositive axon terminals formed close contacts or asymmetric synapses with the neuronal soma or dendrites of the collateral projections into the thalamus and LPB in Vc

To further investigate whether the Vc collateral projection neurons previously identified directly received peripheral nociceptive afferents, a triple-labeled immunofluorescence histochemical technique for CGRP, TMR and FG was used. Under a confocal laser scanning microscope, CGRP-LI was mainly observed in axonal terminals in the superficial layers of the Vc (Fig. 9a, b). No CGRP-positive products were identified in the cell bodies or dendrite profiles. Some CGRP-LI axonal terminals were observed to be in close apposition with TMR/FG double-labeled neuronal cell bodies and dendrites in laminae I and II of the Vc (Fig. 9f).

The pre-embedded triple immune-electron microscopic method was performed in three rats to further examine whether CGRP-LI axon terminals may form synaptic contacts with the PBN and thalamus collateral projection neurons in the Vc. After the WGA-HRP injection into the right thalamus and the FG injection into the left $\mathrm{PBN}$, retrograde tract tracing combined with 
Table 1 Number of TMR, FG and VGLUT2 mRNA-labeled neurons in the Vo, Vi, and Vc of R4, R7 and R13

\begin{tabular}{llll}
\hline & $V 0$ & $V i$ & $V c$ \\
\hline$(1) T M R$ & $92 \pm 8$ & $176 \pm 9$ & $65 \pm 8$ \\
$(2) F G$ & $155 \pm 9$ & $222 \pm 11$ & $73 \pm 4.5$ \\
$(3) \mathrm{VGLUT2}$ mRNA & $1347 \pm 96$ & $732 \pm 27$ & $6285 \pm 132$ \\
$(4) \mathrm{TMR}+\mathrm{FG}$ & $83 \pm 9$ & $163 \pm 6$ & $32 \pm 3.3$ \\
$(5)[(4) /(1)] \times 100$ & $(90.5 \pm 1.8) \%$ & $(92.5 \pm 1.9) \%$ & $(49.6 \pm 1.0) \%$ \\
$(6)[(4) /(2)] \times 100$ & $(53.5 \pm 2.5) \%$ & $(73.6 \pm 1.2) \%$ & $(43.7 \pm 1.9) \%$ \\
$(7) \mathrm{TMR}+\mathrm{VGLUT2}$ mRNA & $81 \pm 6$ & $162 \pm 18$ & $42 \pm 5$ \\
$(8)[(7) /(1)] \times 100$ & $(88.2 \pm 2.5) \%$ & $(92.0 \pm 5.3) \%$ & $(64.5 \pm 1.0) \%$ \\
$(9)[(7) /(3)] \times 100$ & $(6.0 \pm 0.2) \%$ & $(22.2 \pm 1.6) \%$ & $(0.7 \pm 0.1) \%$ \\
$(10) \mathrm{FG}+\mathrm{VGLUT2}$ mRNA & $130 \pm 10$ & $214 \pm 13$ & $66 \pm 6$ \\
$(11)[(10) /(2)] \times 100$ & $(83.9 \pm 1.6) \%$ & $(96.6 \pm 1.1) \%$ & $(90.7 \pm 2.9) \%$ \\
$(12)[(10) /(3)] \times 100$ & $(9.7 \pm 0.2) \%$ & $(29.2 \pm 0.7) \%$ & $(1.1 \pm 0.1) \%$ \\
$(13) \mathrm{FG}+\mathrm{TMR}+\mathrm{VGLUT2}$ mRNA & $75 \pm 6$ & $152 \pm 7$ & $27 \pm 3$ \\
$(14)[(13) /(1)] \times 100$ & $(81.7 \pm 3.5) \%$ & $(86.0 \pm 0.7) \%$ & $(42.4 \pm 0.9) \%$ \\
$(15)[(13) /(2)] \times 100$ & $(48.3 \pm 1.7) \%$ & $(68.4 \pm 0.3) \%$ & $(37.3 \pm 1.6) \%$ \\
$(16)[(13) /(3)] \times 100$ & $(5.6 \pm 0.1) \%$ & $(20.7 \pm 0.2) \%$ & $(0.4 \pm 0.0) \%$ \\
$(17)[(13) /(4)] \times 100$ & $(90.3 \pm 4.1) \%$ & $(93.0 \pm 1.2) \%$ & $(85.4 \pm 0.7) \%$ \\
\hline
\end{tabular}

TMR is injected in the right thalamus, and FG is injected into the left PBN. The cell body counts were performed for three rats on the left side. Each figure showing the number of cell bodies of one animal was the average of the three rats ( 5 sections from each rat). The sections were $20 \mu \mathrm{m}$ thick. FG, TMR and VGLUT2 mRNA represent all FG-, TMR- and VGLUT2 mRNA-labeled neurons; data are shown as the mean \pm standard deviation (SD)

Table 2 Number of TMR, FG and VGLUT1 mRNA-labeled neurons in the Vo, Vi, and Vc of R4, R7 and R13

\begin{tabular}{|c|c|c|c|}
\hline & Vo & Vi & Vc \\
\hline (1)TMR & $90 \pm 8$ & $180 \pm 10$ & $63 \pm 7$ \\
\hline (2)FG & $155 \pm 9$ & $223 \pm 8$ & $71 \pm 5.3$ \\
\hline (3)VGLUT1 mRNA & $136 \pm 9$ & $634 \pm 15$ & $241 \pm 12$ \\
\hline (4) $T M R+F G$ & $81 \pm 8$ & $172 \pm 12$ & $31 \pm 4.5$ \\
\hline$(5)[(4) /(1)] \times 100$ & $(89.5 \pm 1.5) \%$ & $(95.1 \pm 1.3) \%$ & $(49.0 \pm 2.6) \%$ \\
\hline (6) $[(4) /(2)] \times 100$ & $(51.8 \pm 2.4) \%$ & $(77.2 \pm 2.8) \%$ & $(43.2 \pm 3.4) \%$ \\
\hline (7)TMR + VGLUT1 mRNA & $17 \pm 4$ & $1 \pm 0.8$ & $3 \pm 2$ \\
\hline$(8)[(7) /(1)] \times 100$ & $(19.1 \pm 2.5) \%$ & $(0.5 \pm 0.4) \%$ & $(4.5 \pm 2.1) \%$ \\
\hline (9) $[(7) /(3)] \times 100$ & $(12.6 \pm 1.9) \%$ & $(0.2 \pm 0.1) \%$ & $(1.2 \pm 0.6) \%$ \\
\hline (10)FG + VGLUT1 mRNA & $22 \pm 4$ & $3 \pm 1$ & $3 \pm 2$ \\
\hline$(11)[10) /(2)] \times 100$ & $(14.1 \pm 2.4) \%$ & $(1.3 \pm 0.7) \%$ & $(4.1 \pm 2.0) \%$ \\
\hline$(12)[(10) /(3)] \times 100$ & $(16.1 \pm 2.6) \%$ & $(0.5 \pm 0.2) \%$ & $(1.2 \pm 0.6) \%$ \\
\hline (13)TMR + FG + VGLUT1 mRNA & $24 \pm 5$ & 0 & $1 \pm 0$ \\
\hline$(14)[(13) /(1)] \times 100$ & $(26.8 \pm 3.0) \%$ & 0 & $(1.0 \pm 0.7) \%$ \\
\hline$(15)[(13) /(2)] \times 100$ & $(15.5 \pm 2.2) \%$ & 0 & $(0.9 \pm 0.6) \%$ \\
\hline$(16)[(13) /(3)] \times 100$ & $(17.7 \pm 2.4) \%$ & 0 & $(0.3 \pm 0.2) \%$ \\
\hline$(17)[(13) /(4)] \times 100$ & $(29.9 \pm 3.0) \%$ & $0 \%$ & $(2.0 \pm 1.4) \%$ \\
\hline
\end{tabular}

TMR is injected into the right thalamus, and FG is injected into the left PBN. The cell body counts were performed for three rats on the left side. Each figure showing the number of cell bodies of one animal was the average of the three rats ( 5 sections from each rat). The sections were $20 \mu \mathrm{m}$ thick. FG, TMR and VGLUT1 mRNA represent all FG-, TMR- and VGLUT1 mRNA-labeled neurons; data are shown as the mean \pm standard deviation (SD) 


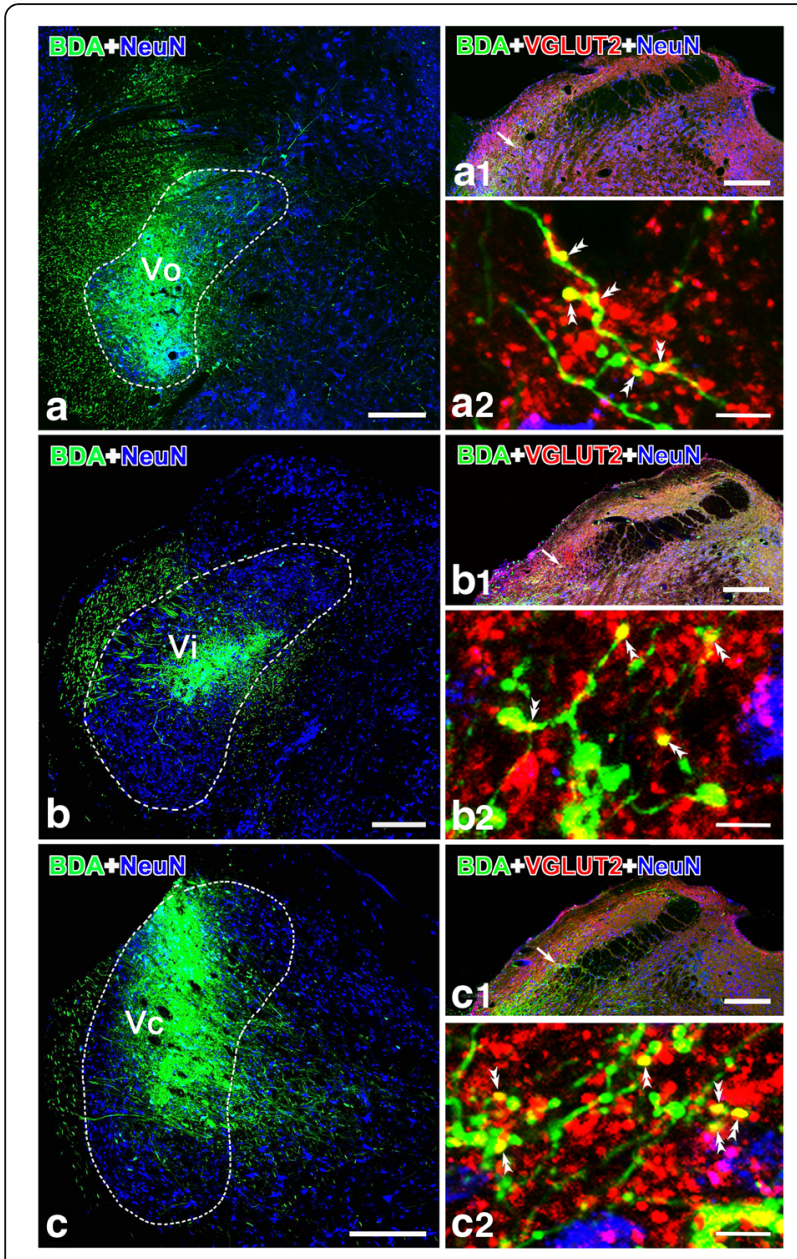

Fig. 5 After the BDA injection into the $V_{0}(\mathbf{a}), V_{i}(\mathbf{b})$ or $V_{c}(\mathbf{c})$, many BDA-labeled terminals in the ipsilateral PBN showed VGLUT2-LI (Vo: a1-a2; Vi: b1-b2; Vc: c1-c2). The site of BDA injection and the BDA anterogradely labeled terminals are visualized with fluorescein (green). VGLUT2-LI axon terminals are visualized with Alexa 594 (red), and neuronal cell bodies showing NeuN-LI are visualized with Alexa 647 (blue). The areas indicated by the short arrow in (a1), (b1) and (c1) are magnified in (a2), (b2) and (c2), respectively. The double arrowheads in (a2), (b2) and (c2) indicate axon terminals dually labeled with BDA and VGLUT2-LI (yellow). Scale bar $300 \mu \mathrm{m}$ (a, b and c); $200 \mu \mathrm{m}(\mathrm{a} 1, \mathrm{~b} 1$ and $\mathrm{c} 1) ; 5 \mu \mathrm{m}(\mathrm{a} 2, \mathrm{~b} 2$ and c2)

CGRP-like immunohistochemistry was visualized with a typical TMB reaction method for WGA-HRP and the immunogold silver method for FG, whereas CGRPlabeling was identified by the immunoperoxidase method.

In the $\mathrm{Vc}$, electron-dense peroxidase reaction products (DAB reaction) that indicated CGRP labeling were identified within axon terminals, which were filled with round, black, clearly defined synaptic vesicles (Fig. 10c, d). In the superficial layer of the Vc, TMB reaction products that consisted of black crystals with high electronic densities indicating WGAHRP labeling were identified in the cytoplasm and large dendritic processes of neurons that projected to the VPM and Po regions of the thalamus (Fig. 10a, d, double arrowheads). Some of the cytoplasm and large dendritic processes of neurons were also labeled with silver-intensified gold particles indicating FG labeling (Fig. 10b, d, arrows), which projected to the parabrachial region. Some of the neuronal cell bodies or dendrite profiles in the superficial layer of the Vc often showed WGA-HRP/FG double-labeling (Fig. 10d). Moreover, the CGRP-LI axon terminals were often observed in asymmetric synaptic contact with dendritic profiles that were labeled retrogradely with WGA-HRP/FG (Fig. 10d), which indicates that these neurons collaterally project to the thalamus and PBN.

\section{Discussion}

It has been reported that some projection neurons in lamina I of the spinal dorsal horn [26] or medullary dorsal horn $(\mathrm{Vc})$ of the rat [4] send their axons to both the thalamus and the PBN by way of axon collaterals; however, no previous study has reported the existence of these neurons in the Vo, Vi, and Vc or which VGLUTs may be expressed in the T-T and T-P collateral projection neurons in the Vsp. Thus, in the present study, retrograde tract tracing was performed to examine whether Vsp neurons may be labeled with two types of retrograde tracers that were injected into the thalamus and PBN of each rat. FISH histochemistry was further performed to examine the expression of VGLUT1 mRNA and VGLUT2 mRNA in these collaterally projecting neurons.

The results of the present study have indicated the existence of collaterally projecting neurons in the $\mathrm{Vo}, \mathrm{Vi}$ and $\mathrm{Vc}$, and these collateral projection neurons in the Vo, Vi and Vc exclusively expressed VGLUT2 mRNA and not VGLUT1 mRNA, with the exception of a few Vo collateral projection neurons that were VGLUT1 mRNA-positive. Moreover, the collaterally projecting neurons in the Vc may be related to the transmission of orofacial nociceptive information.

\section{VGLUT1 and VGLUT2 mRNA-expressing neurons in Vsp}

\section{send axon collaterals to both the thalamus and the PBN} It has been reported that the trigeminothalamic fibers of the rat project to the thalamus bilaterally with contralateral predominance [27, 28]. Therefore, in the present study, TMR was injected into the contralateral thalamus, and it was ensured that the injection site covered the VPM and Po. TMR-labeled neurons were distributed in all subdivisions of the contralateral Vsp ( $\mathrm{Vo}, \mathrm{Vi}$, and $\mathrm{Vc}$ ). They were most prevalent in the Vi, followed by the Vo, with the smallest in number in the Vc. These data appear to be in fairly good accordance with data previously reported in the rat $[15,29]$. The TMR-labeled neurons 


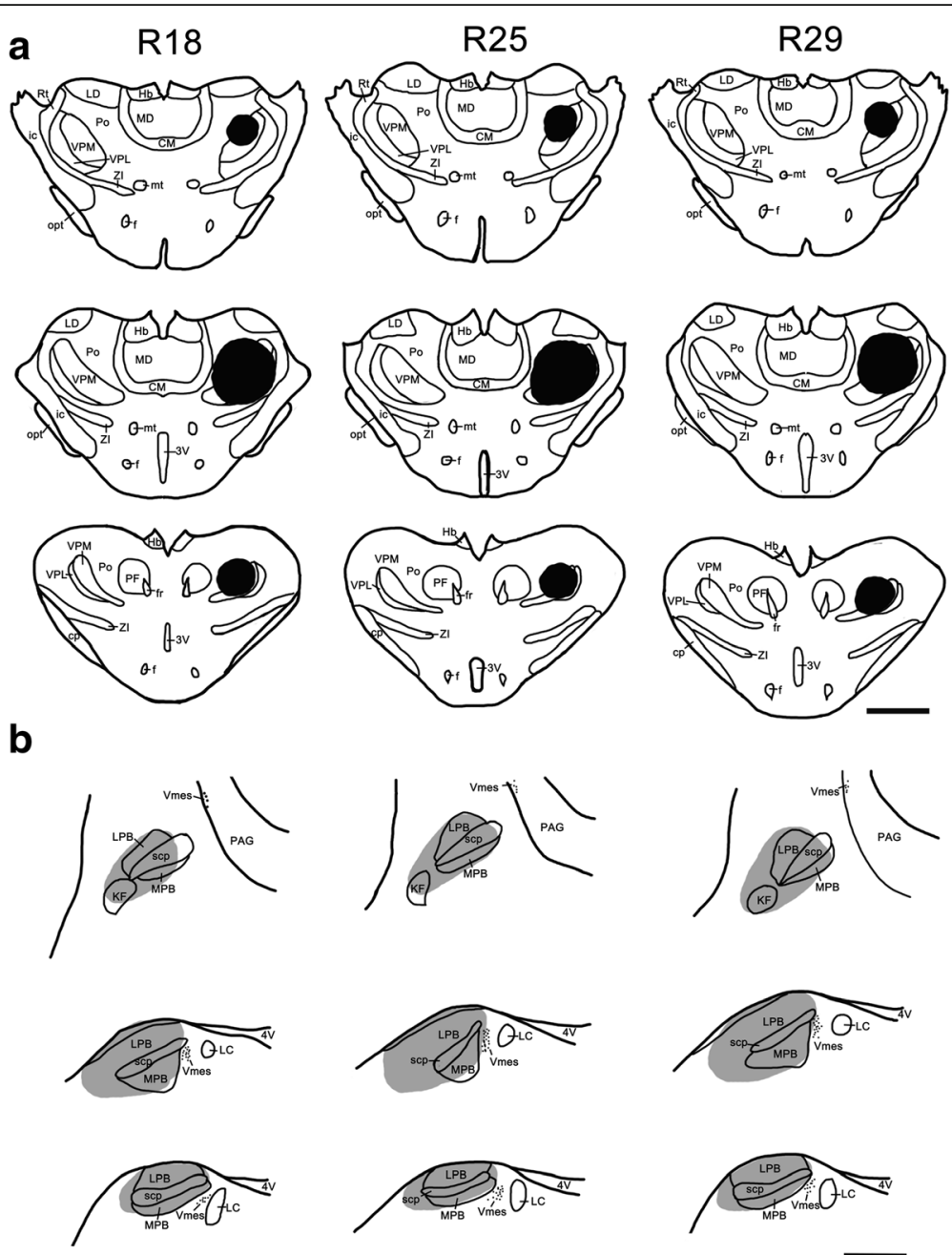

Fig. 6 Projection drawings of the sites of TMR injection into the thalamus and FG injection into the PBN in three rats (R18, R25, and R29) that received formalin injection prior to perfusion. a Three different sections from rostral to caudal of the thalamus show the TMR injection into the right side of the thalamus site involving the VPM, the Po and their vicinities. $\mathbf{b}$ FG was injected into the left PBN, with the densest core

(blackened areas) covering parts throughout the PBN and the KF. Scale bar $2 \mathrm{~mm}(\mathbf{a}) ; 1 \mathrm{~mm}$ (b)

in the Vc showed a laminar pattern, with most of the retrogradely labeled neurons in the superficial layers (laminae I and II) as previously reported $[4,30]$. Previous studies regarding direct projection from the Vo to the thalamus are contradictory: studies $[29,31]$ have shown retrogradely labeled neurons in the Vo, whereas other studies [2, 32] have not. In the present study, we observed TMR-labeled neurons throughout the Vo, with more neurons in the ventrolateral part. This distribution pattern is similar to that reported by Guy et al. [31].

It has been established that the projection fibers from the $\mathrm{Vc}$ to the PBN in the rat mainly terminate in the $\mathrm{PBN}$ portions lateral and ventromedial to the superior cerebellar peduncle [4, 33-35]. These PBN areas of termination of projection fibers from the ipsilateral Vsp ( Vo, Vi, Vc) appeared to be included in the FG injection sites in the present study. As the PBN is dorsomedial to the $\mathrm{Vp}$, the injection site was strictly limited within the PBN without contaminating the Vp, which receives direct projections from the Vsp. The FG-labeled neurons were observed in the bilateral Vsp with ipsilateral predominance. This finding is consistent with previous studies that described direct Vsp projections to the PBN with ipsilateral predominance in the rat [33, 35-37]. According to the present results, the PBN-projecting neurons were distributed among the entire $\mathrm{Vo}$ and $\mathrm{Vi}$, whereas Vc neurons that send projections to the PBN were mainly located in the superficial layer, which is also consistent with previous studies $[4,34,35,38]$.

In the present study, following the TMR injection contralaterally into the thalamus and the FG injection ipsilaterally into the PBN, TMR/FG double-labeled neurons in the Vo, Vi and Vc were frequently encountered. Neurons dually labeled for TMR and FG were distributed in 


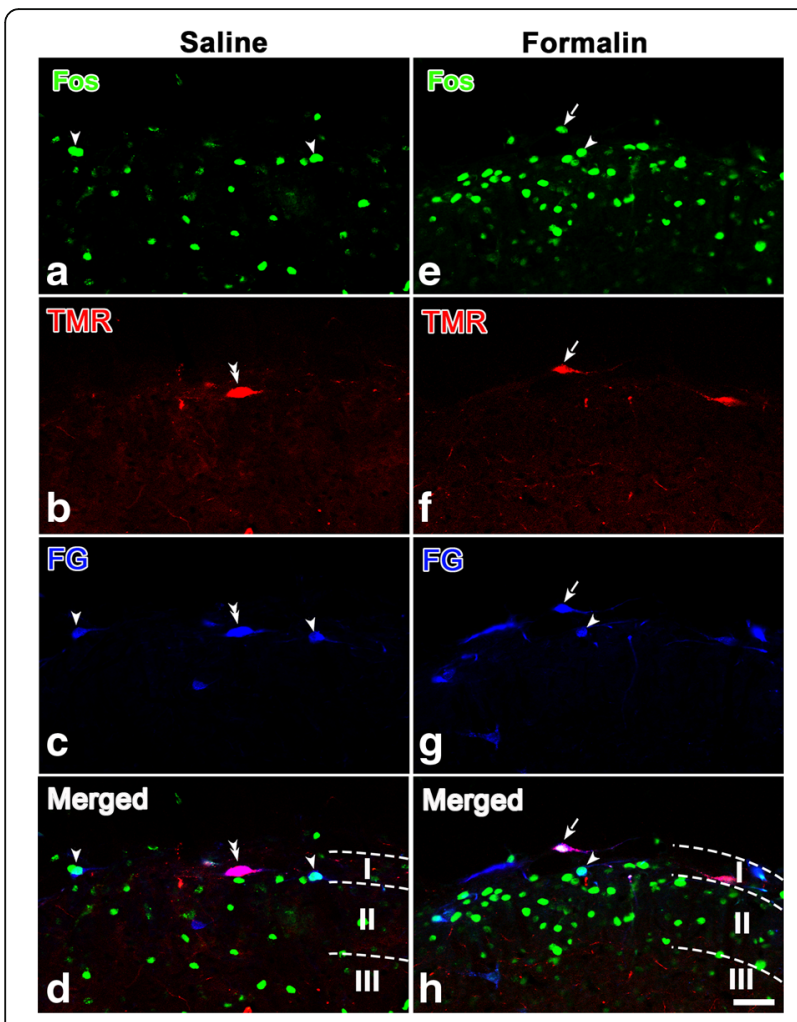

Fig. $7 \mathrm{Vc}$ neurons that send axon collaterals to both the thalamus and PBN are Fos positive after a subcutaneous 4\% formalin injection into the left upper lip. TMR was injected into the right VPM and Po of the thalamus, and FG was injected into the left PBN. TMR, FG and Fos immunoreactivity in the Vc are visualized with Alexa 594 (red), Alexa 647 (blue) and fluorescein (green), respectively. a-d Representative section from animals injected with normal saline (R4, R7, and R13, Fig. 2) and showing triple-labeled with TMR, FG and Fos. e-h Representative section from animals injected formalin (R18, R25, and R29, Fig. 6) and showing triple-labeled with TMR, FG and Fos. The double arrowheads in (b, $\mathbf{c}$ and $\mathbf{d}$ ) indicate neurons doublelabeled with TMR/FG. The single arrowheads in (a-h) indicate neurons double-labeled with FG and Fos. The arrows in e-h indicate neurons triple-labeled with TMR/FG/Fos. I, II and III in (d) and (h) represent the laminae I, II and III of Vc. Scale bar $50 \mu \mathrm{m}$

all subdivisions of the Vsp ( $\mathrm{Vo}, \mathrm{Vi}$, and $\mathrm{Vc})$; they were most prevalent in the $\mathrm{Vi}$, followed by the $\mathrm{Vo}$, with the smallest number in the $V_{c}$ (Table 1). In the Vc, the TMR/FG double-labeled neurons were distributed in a laminar pattern, with the vast majority in lamina I. A previous study [4] also indicated that neurons in the Vc sent collateral projections to both the thalamus and the PBN, with more than $90 \%$ of the projecting neurons distributed in lamina I. Thus, the Vc neurons doublelabeled with TMR/FG, which were observed in the present study, are considered to represent fairly well the Vc neurons that send their axons both ipsilaterally to the $\mathrm{PBN}$ and contralaterally to the thalamus by way of axon collaterals. Moreover, the results of the present study have further indicated the existence of neurons in the $\mathrm{Vi}$ and Vo that also send collateral projection to both the $\mathrm{PBN}$ and the thalamus; however, these collateral projection neurons have not been reported in previous studies.

In the present study, FISH histochemistry for VGLUT1 or VGLUT2 mRNA was combined with double retrograde tract tracing using TMR injected into the thalamus and FG injected into the PBN. The results indicated that most TMR/FG doubly labeled Vsp neurons express VGLUT2 mRNA (90.3\% in the Vo, 93.0\% in the $\mathrm{Vi}$, and $85.4 \%$ in the $\mathrm{Vc}$ ), whereas almost no TMR/FG-labeled Vi and Vc neurons express VGLUT1 mRNA (Tables 1 and 2). Dual FISH histochemistry performed in a previous study [16] also indicated that no single Vsp neurons co-express VGLUT1 and VGLUT2 mRNAs. Thus, it was assumed that glutamatergic T-T and T-P collateral projection neurons in the Vsp mainly express VGLUT2 mRNA.

\section{Collateral projection neurons in Vc are related to the transmission of orofacial nociceptive information}

The $\mathrm{Vc}_{\mathrm{c}}$ is often referred to as the medullary dorsal horn and is considered to be homologous to the spinal dorsal horn both structurally and functionally [39]. The superficial laminae of the Vc contains many neurons that constitute the main relay for nociceptive primary afferents from the orofacial regions [39-41], and previous studies have indicated that substance $\mathrm{P}$ (SP)-containing small-diameter primary afferent fibers and CGRP-LI primary afferent fibers terminate mainly in laminae I and II [42-45]. Thus, in the present study, when some TMR/FG double-labeled soma and dendrites of neurons in laminae I and II of the $\mathrm{VC}_{\mathrm{C}}$ were in apposition to CGRP-LI terminals under the confocal laser-scanning microscope, they were assumed to receive and transmit nociceptive inputs. Furthermore, the results of the electron microscopy also indicated that CGRP-LI axon terminals (labeled with $\mathrm{DAB}$ reaction) formed asymmetric synapses with the soma or dendrite profiles of the TMR/FG doublelabeled collateral projection neurons in the Vc. In accordance with the present data, previous studies in primates have indicated that many nociceptive neurons in the Vc receive direct primary nociceptive afferent input and send projection fibers to both the $\mathrm{PBN}$ and the thalamus, including the VPM and Po, by way of axon collaterals [4, 26, 46-48].

Furthermore, the nociceptive nature of Vc neurons that were retrogradely labeled with TMR and FG injected into the thalamus and PBN was identified by the expression of Fos-LI after the injection of formalin solution into the upper lip of rats. Previous studies have shown that noxious stimulation of different orofacial sites induced Fos-LI in 

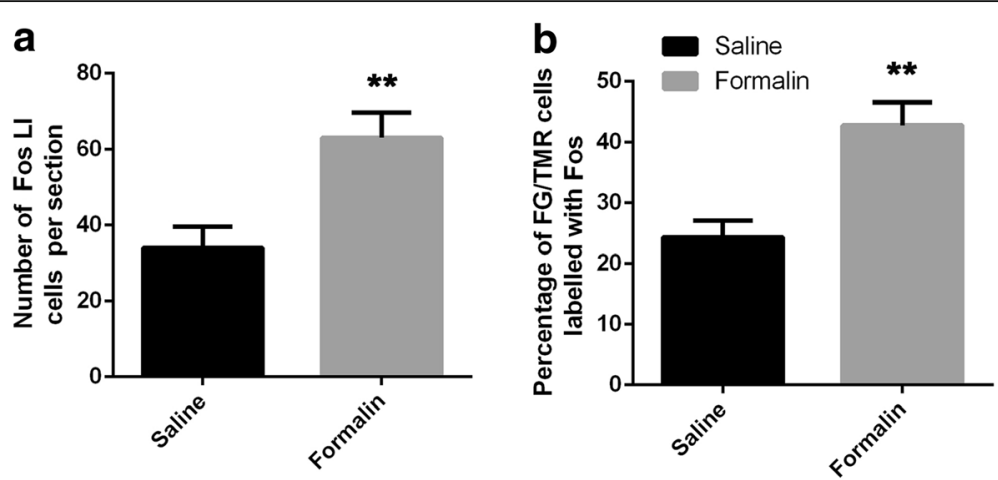

Fig. 8 Comparison of the number of Fos-like immunoreactive (LI) neuronal cells in the superficial layer (laminae I and II) of the Vc in rats injected with normal saline and rats injected with formalin. a Compared with rats injected with normal saline, the number of Fos-LI cells per section in the superficial layer of the Vc significantly increased after the injection of formalin into the upper lip of rats. $\mathbf{b}$ The percentage of FG/TMR double-labeled neurons in one section in the superficial layer of the Vc showed Fos-LI substantially increased in rats injected with formalin. ${ }^{*} P<0.001,30$ sections from 3 rats

the ipsilateral Vc, mainly in laminae I and II [18, 49-52]. Therefore, Fos-LI has often been used for the investigation of somatotopy in the trigeminal nociceptive pathways $[18,53,54]$. In the present study, after subcutaneous injection of formalin into the upper lip of rats, Fos-LI was induced in many neurons in the Vc, particularly in the superficial laminae of the dorsomedial part. This distribution pattern of Fos-LI was consistent with previous studies $[18,19,55,56]$ and appeared to be compatible with the somatotopy of the projection of the trigeminal nerve [24]. We also performed triple-labeling of TMR/FG/Fos to identify the expression of Fos-LI in TMR/FG double-labeled neurons. The neurons that supply relatively localized orofacial regions are somatotopically organized within the Vc [24]. We noxiously stimulated only the upper lip, and it may be assumed that only some of the nociceptive neurons in the $\mathrm{Vc}_{\mathrm{c}}$ were activated. Thus, the present result that $34.0 \%$ of TMR/FG doublelabeled neurons expressed Fos-LI may indicate that a substantial proportion of the collateral projection neurons in the $\mathrm{Vc}$ are activated by noxious stimulation of the orofacial region.
Functional implications of the glutamatergic collateral projection neurons in Vsp

The thalamus and PBN are two nuclei with distinctly different roles. As shown in the present results, the injection site in the thalamus covered the VPM and Po. These two thalamic relay nuclei receive their afferent input from the Vsp and project to the somatosensory cortex in a complementary pattern $[15,16,57,58]$. Both nuclei are critical in the formation of discriminative somatic sensation of orofacial regions [39, 59, 60]. The function of the PBN is relatively complicated. It is involved not only in gustatory functions [61-63] and autonomic regulatory processes $[38,64-68]$ but also affective processes [69-71], particularly in the affective aspects of pain $[5,38,72,73]$. The information conveyed by the T-P pathways likely contributes more to the affective component of the pain experience than to the discriminative somatic sensation [39, 74]. In brief, the T-T and T-P projections are related to the discriminative somatic sensation and the affective component of orofacial sensation, respectively.

In situ hybridization detection was used for VGLUT1 and VGLUT2 mRNA, which have been well

Table 3 Number of neurons labeled with FG, TMR and (or) Fos in the Vc of R18, R25 and R29

\begin{tabular}{lllll}
\hline & Lamina I & Lamina II & Lamina III & Total \\
\hline (1)TMR & $92 \pm 9(59.3 \pm 1.5) \%$ & $12 \pm 3(7.9 \pm 2.5) \%$ & $51 \pm 7(33.1 \pm 0.3) \%$ & $142 \pm 18$ \\
$(2) F G$ & $81 \pm 8(57.5 \pm 1.8) \%$ & $21 \pm 4(15.5 \pm 4.0) \%$ & $39 \pm 6(27.6 \pm 0.7) \%$ & $155 \pm 18$ \\
$(3)$ Fos & $344 \pm 18(29.3 \pm 0.4) \%$ & $287 \pm 11(24.5 \pm 1.7) \%$ & $541 \pm 16(46.2 \pm 0.5) \%$ & $1172 \pm 46$ \\
$(4)$ TMR + FG & $29 \pm 6(64.0 \pm 4.4) \%$ & $7 \pm 2(15.5 \pm 6.5) \%$ & $11 \pm 4(22.1 \pm 2.9) \%$ & $47 \pm 12$ \\
$(5)$ TMR + FG + Fos & $13 \pm 4(77.8 \pm 2.1) \%$ & $2 \pm 1(14.2 \pm 7.0) \%$ & $2 \pm 0(10.4 \pm 1.6) \%$ & $16 \pm 5$ \\
$(6)[(5) /(4)] \times 100$ & $(42.1 \pm 5.8) \%$ & $(29.4 \pm 3.4) \%$ & $(16.4 \pm 3.1) \%$ & $(34.4 \pm 2.4) \%$ \\
\hline
\end{tabular}

TMR is injected into the collateral thalamus, and FG is injected into the ipsilateral PBN. The cell body counts were performed for three rats on the ipsilateral side of the FG injection site. Each figure showing the number of cell bodies of one animal was the average of the three rats (10 sections from each rat). The sections were $20 \mu \mathrm{m}$ thick. FG, TMR and Fos represent all FG-, TMR- and Fos-labeled neurons; data are shown as the mean \pm standard deviation (SD) 

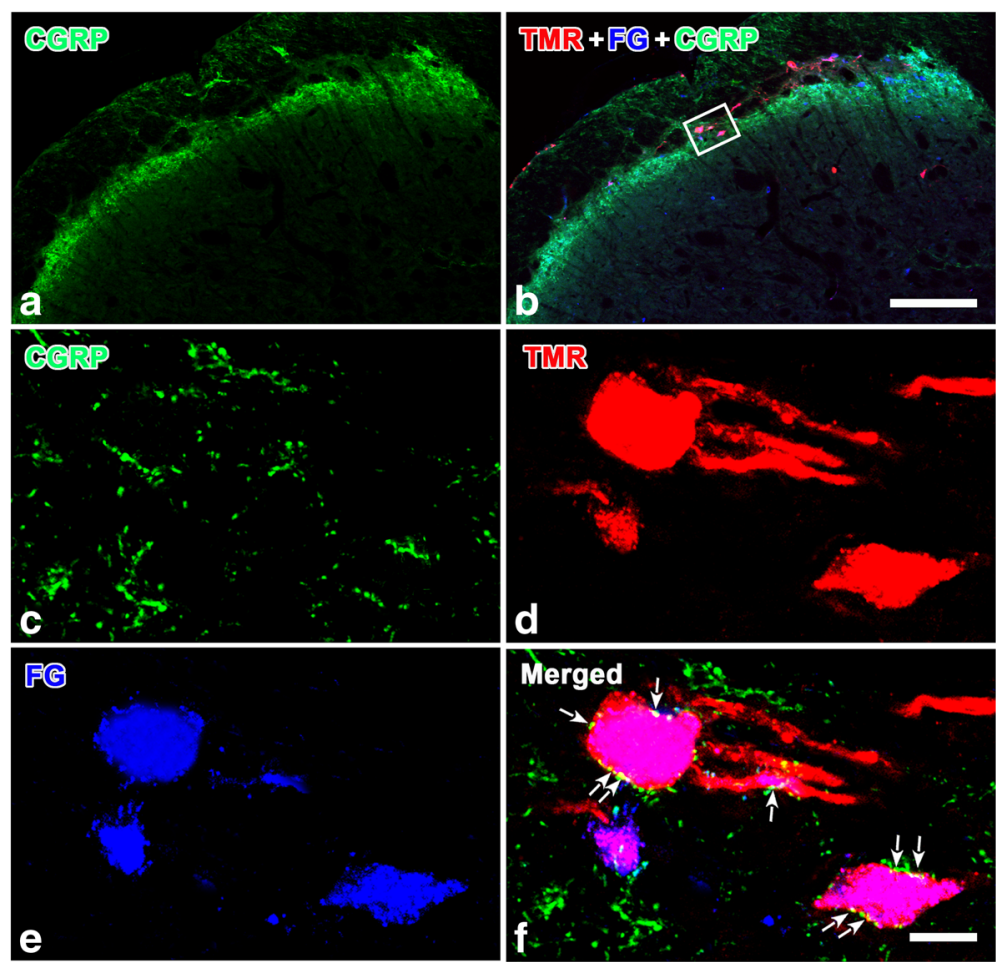

Fig. 9 CGRP-positive terminals have close contacts with collateral projection neurons in the Vc superficial layer. TMR was injected into the right VPM and Po of the thalamus, and FG was injected into the left PBN in three rats (R4, R7, and R13, Fig. 2). TMR, FG and CGRP immunoreactivity in the superficial layer of the Vc are visualized with Alexa 594 (red), Alexa 647 (blue) and fluorescein (green), respectively. The boxed area in (b) is magnified in (c-f). The arrows in $\mathrm{f}$ indicate that some CGRP-LI axonal terminals are in close contact with TMR/FG double-labeled cell body or dendritic profiles. Scale bar $200 \mu \mathrm{m}$ (in a and b); $20 \mu \mathrm{m}$ (in c-f)

established as the specific markers for glutamatergic neurons in the CNS [10-14, 75-78]. The distribution of VGLUT1 and VGLUT2 in the CNS exhibited a complementary pattern [14], which indicates that there may be a distinct functional difference between these two proteins. In the Vsp, as shown in a previous study, the distribution and projection of VGLUT1 and VGLUT2 mRNA-positive neurons are also different [17]. VGLUT1 mRNA-expressing neurons are distributed in the Vo, Vi, and Vc, and some VGLUT1 mRNA-expressing neurons in the $\mathrm{Vi}$, and a few neurons in the Vo send VGLUT1-positive axon terminals to the trigeminal motor nucleus [17] and cerebellum [15]. Moreover, nearly all Vo, Vi and Vc neurons express VGLUT2 mRNA signals and send VGLUT2positive axon terminals to the contralateral thalamus [15]. The current findings showed that Vsp neurons sending collateral projections to the thalamus and PBN mainly expressed VGLUT2 mRNA signals, which indicates that VGLUT2 and not VGLUT1 was potentially involved in the transmission of orofacial information from the Vsp to the thalamus and PBN.

The subnuclei of the Vsp ( Vo, Vi, and Vc) have been indicated to be different in their functional properties: they are related to different types of sensory information from orofacial regions [24]. Among these nuclei, the Vc has been widely investigated for its role in the transmission of orofacial nociceptive information. According to the results of the present and previous studies, Vc neurons sending collateral projections to the thalamus and PBN were mainly distributed in the superficial laminae $[4,79]$. The superficial laminae of the Vc are the primary gateway for the peripheral noxious information transmitted from the orofacial region [39, 80, 81]. CGRP is regarded as a key mediator released from trigeminal ganglion neurons to the superficial laminae of the Vc after the stimulation of sensory nerve endings and is responsible for the transmission of pain sensation [82]. In the present study, we determined that CGRP-LI terminals formed asymmetric synapses with somatic or dendritic profiles of the neurons projecting collaterally to the thalamus and PBN in the superficial laminae of the Vc. The collateral projecting neurons were also activated after painful stimulation of the lip. It may be assumed from the present results that the VGLUT2-positive neurons in the superficial laminae of the Vc may receive pain information from the primary afferent fibers of the trigeminal nerve and simultaneously relay it to the thalamus and PBN. 

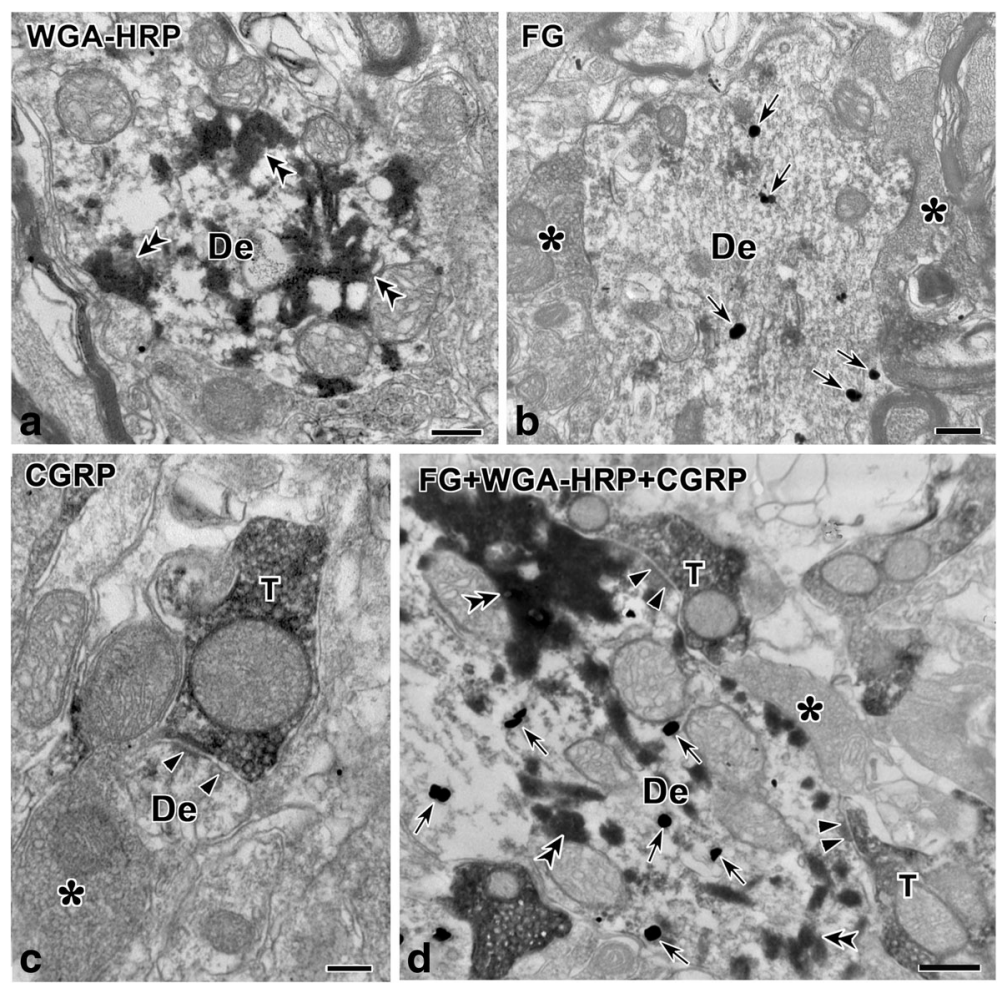

Fig. 10 Electron microphotographs of the superficial layer of the Vc after triple-labeling with WGA-HRP, FG and CGRP. Axon terminals labeled with CGRP (c, d) form asymmetric synapses (black arrowheads) with WGA-HRP and FG dually labeled dendritic profiles (De) in the superficial layer of the Vc after a WGA-HRP injection into the right thalamus and an FG injection into the left LPB. CGRP-LI is represented with electron-dense, amorphous products of DAB reaction ( $\mathbf{c}, \mathbf{d}$ ). Silver-intensified gold particles produced with the immunogold-silver method indicate FG labeling (b, $\mathbf{d}$; arrows). Electron-dense, amorphous material produced by the peroxidase reaction indicate WGA-HRP labeling (TMB reaction; $\mathbf{a}$, $\mathbf{d}$; double arrowheads). De, dendritic profiles; T, CGRP-LI axon terminals; ${ }^{*}$, CGRP-negative axon terminals. Scale bar $250 \mathrm{~nm}$ (a, b, c and d)

According to the present data, the VGLUT2-expressing neurons in the $\mathrm{Vi}$ and Vo also send axonal collaterals to the thalamus and PBN. Previous studies have shown that the $\mathrm{Vi}$ is primarily concerned with the transmission of tactile sensation and low-threshold signals from orofacial regions, and Vi neurons predominately respond to the stimulation of individual vibrissae in rats $[83,84]$. Vo neurons are closely related to the transmission of orofacial proprioceptive sensation [24]. Thus, it is plausible that VGLUT2expressing neurons in the Vi or Vo may relay orofacial tactile sensation or proprioceptive sensation, respectively, to the thalamus and PBN. The T-T projection from the $\mathrm{Vi}$ is related to discriminative orofacial tactile sensation from the vibrissae [24]. The T-P projection from the $\mathrm{Vi}$ may be related to affective reactions evoked by orofacial tactile sensation from the vibrissae. Moreover, it has been reported that amputation of vibrissae may induce anxiety in rats [85]. The T-T and T-P projections from the Vo are mainly concerned with discriminative orofacial proprioceptive sensation and concomitant affective reactions, respectively [24]. Whether the discriminative sensation and affective reactions of orofacial tactile and proprioceptive sensation are transmitted by these collateral projection neurons in the $\mathrm{Vi}$ and Vo remains to be discovered. Our data further confirmed that trigemino-thalamic and trigemino-parabrachial collateral projection neurons were VGLUT2 mRNApositive, which further indicates that orofacial nociceptive information uses glutamate as a neurotransmitter recruited by VGLUT2.

\section{Conclusions}

In summary, the present study indicates T-T and T-P collateral projection neurons that send their axon terminals to both the thalamus and the PBN by way of axon collaterals are mainly localized in the Vo, Vi and Vc. Glutamatergic T$\mathrm{T}$ and T-P collateral projection neurons in the $\mathrm{Vo}, \mathrm{Vi}$ and Vc mainly express VGLUT2 mRNA. Some T-T and T-P collateral projection neurons that express Fos-LI in the Vc are closely related to the transmission of orofacial nociceptive information after subcutaneous injection of formalin into the upper lip. Moreover, the collateral projection neurons in the Vc that formed synaptic contacts with CGRP-LI primary afferent axon terminals were also considered nociceptive. 


\section{Abbreviations}

$3 \mathrm{~V}$ : Third ventricle; $4 \mathrm{~V}$ : Fourth ventricle; CM: Central medial thalamic nucleus; cp: Cerebral peduncle; f: Fornix; FG: Fluoro-Gold; FISH: Fluorescence in situ hybridization; fr: Fasciculus retroflexus; Hb: Habenular nucleus; ic: Internal capsule; KF: Kölliker-Fuse nucleus; LC: Locus coeruleus; LD: Laterodorsal thalamic nucleus; LPB: Lateral parabrachial nucleus; MD: Mediodorsal thalamic nucleus; MPB: Medial parabrachial nucleus; mt: Mammillothalamic tract; opt: Optic tract; PAG: Periaqueductal gray; PBN: Parabrachial nucleus; PF: Parafascicular thalamic nucleus; Po: Posterior thalamic nuclear group; Rt: Reticular thalamic nucleus; scp: Superior cerebellar peduncle; TMR: Tetramethylrhodamine; T-P: Trigeminoparabrachial (T-P) pathways; T-T: Trigemino-thalamic pathways; Vc: Caudal subnucleus of spinal trigeminal nucleus; VGLUT: Vesicular glutamate transporter; Vi: Interpolar subnucleus of spinal trigeminal nucleus; Vmes: Trigeminal mesencephalic nucleus; Vo: Oral subnucleus of spinal trigeminal nucleus; Vp: Principal sensory trigeminal nucleus; VPL: Ventral posterolateral thalamic nucleus; VPM: Ventral posteromedial thalamic nucleus; Vsp: Spinal trigeminal nucleus; ZI: Zona incerta

\section{Acknowledgements}

Not applicable.

\section{Funding}

This work was supported by the National Natural Science Foundation of China (No. 81571074).

\section{Availability of data and materials}

The data supporting the findings of this study are included within the article.

\section{Authors' contributions}

$J L L, Y Q L$ and TC designed the experiments; CKZ conducted the experiments; $\mathrm{TZ}$ and $\mathrm{YCL}$ assisted with the immunoelectron microscopic staining; $Y \mathrm{O}$ assisted with cell counting and statistics; CKZ and ZHL wrote the manuscript; and JLL, YQL and YLD helped revise the manuscript. All authors read and approved the final manuscript.

\section{Ethics approval}

Animal use and care was approved by the Animal Care and Use Committee at the Fourth Military Medical University. Consent to participate is not applicable.

\section{Consent for publication}

Not applicable.

\section{Competing interests}

The authors declare that they have no competing interests.

\section{Publisher's Note}

Springer Nature remains neutral with regard to jurisdictional claims in published maps and institutional affiliations.

\section{Author details}

'Department of Anatomy and K.K. Leung Brain Research Centre, The Fourth Military Medical University, Xi'an, People's Republic of China. ${ }^{2}$ Student Brigade, Fourth Military Medical University, Xi'an, People's Republic of China.

Received: 15 January 2018 Accepted: 22 March 2018

Published online: 12 April 2018

\section{References}

1. Erzurumlu RS, Killackey HP. Efferent connections of the brainstem trigeminal complex with the facial nucleus of the rat. J Comp Neurol. 1979;188:75-86.

2. Fukushima T, Kerr FW. Organization of trigeminothalamic tracts and other thalamic afferent systems of the brainstem in the rat: presence of gelatinosa neurons with thalamic connections. J Comp Neurol. 1979;183:169-84.

3. Yoshida A, Chen K, Moritani M, Yabuta NH, Nagase Y, Takemura M, Shigenaga $Y$. Organization of the descending projections from the parabrachial nucleus to the trigeminal sensory nuclear complex and spinal dorsal horn in the rat. J Comp Neurol. 1997;383:94-111.

4. Li J, Xiong K, Pang Y, Dong Y, Kaneko T, Mizuno N. Medullary dorsal horn neurons providing axons to both the parabrachial nucleus and thalamus. J Comp Neurol. 2006;498:539-51.
5. Light AR, Sedivec MJ, Casale EJ, Jones SL. Physiological and morphological characteristics of spinal neurons projecting to the parabrachial region of the cat. Somatosens Mot Res. 1993;10:309-25.

6. Ni B, Wu X, Yan GM, Wang J, Paul SM. Regional expression and cellular localization of the $\mathrm{Na}(+)$-dependent inorganic phosphate cotransporter of rat brain. J Neurosci. 1995;15:5789-99.

7. Herzog E, Bellenchi GC, Gras C, Bernard V, Ravassard P, Bedet C, Gasnier B, Giros B, El Mestikawy S. The existence of a second vesicular glutamate transporter specifies subpopulations of glutamatergic neurons. J Neurosci 2001; $21: R C 181$

8. Hisano S, Hoshi K, Ikeda Y, Maruyama D, Kanemoto M, Ichijo H, Kojima I, Takeda J, Nogami H. Regional expression of a gene encoding a neuronspecific $\mathrm{Na}(+)$-dependent inorganic phosphate cotransporter (DNPI) in the rat forebrain. Brain Res Mol Brain Res. 2000;83:34-43.

9. Gras C, Herzog E, Bellenchi GC, Bernard V, Ravassard P, Pohl M, Gasnier B, Giros B, El Mestikawy SA. Third vesicular glutamate transporter expressed by cholinergic and serotoninergic neurons. J Neurosci. 2002;22:5442-51.

10. Fremeau RT Jr, Kam K, Qureshi T, Johnson J, Copenhagen DR, StormMathisen J, Chaudhry FA, Nicoll RA, Edwards RH. Vesicular glutamate transporters 1 and 2 target to functionally distinct synaptic release sites. Science. 2004;304:1815-9.

11. Fremeau RT Jr, Troyer MD, Pahner I, Nygaard GO, Tran CH, Reimer RJ, Bellocchio EE, Fortin D, Storm-Mathisen J, Edwards RH. The expression of vesicular glutamate transporters defines two classes of excitatory synapse. Neuron. 2001;31:247-60.

12. Fremeau RT Jr, Voglmaier S, Seal RP, Edwards RH. VGLUTS define subsets of excitatory neurons and suggest novel roles for glutamate. Trends Neurosci. 2004;27:98-103.

13. Fujiyama F, Furuta T, Kaneko T. Immunocytochemical localization of candidates for vesicular glutamate transporters in the rat cerebral cortex. J Comp Neurol. 2001:435:379-87.

14. Kaneko T, Fujiyama F. Complementary distribution of vesicular glutamate transporters in the central nervous system. Neurosci Res. 2002;42:243-50.

15. Ge SN, Li ZH, Tang J, Ma Y, Hioki H, Zhang T, Lu YC, Zhang FX, Mizuno N, Kaneko T, Liu YY, Lung MS, Gao GD, Li JL. Differential expression of VGLUT1 or VGLUT2 in the trigeminothalamic or trigeminocerebellar projection neurons in the rat. Brain Struct Funct. 2014;219:211-29.

16. Ge SN, Ma YF, Hioki H, Wei YY, Kaneko T, Mizuno N, Gao GD, Li JL. Coexpression of VGLUT1 and VGLUT2 in trigeminothalamic projection neurons in the principal sensory trigeminal nucleus of the rat. J Comp Neurol. 2010;518:3149-68.

17. Pang YW, Ge SN, Nakamura KC, Li JL, Xiong KH, Kaneko T, Mizuno N. Axon terminals expressing vesicular glutamate transporter VGLUT1 or VGLUT2 within the trigeminal motor nucleus of the rat: origins and distribution patterns. J Comp Neurol. 2009;512:595-612.

18. Strassman AM, Vos BP, Mineta $Y$, Naderi S, Borsook D, Burstein R. Fos-like immunoreactivity in the superficial medullary dorsal horn induced by noxious and innocuous thermal stimulation of facial skin in the rat. J Neurophysiol. 1993;70:1811-21.

19. Oyamaguchi A, Abe T, Sugiyo S, Niwa H, Takemura M. Selective elimination of isolectin B4-binding trigeminal neurons enhanced formalin-induced nocifensive behavior in the upper lip of rats and c-Fos expression in the trigeminal subnucleus caudalis. Neurosci Res. 2016;103:40-7.

20. Sugiyo S, Uehashi D, Satoh F, Abe T, Yonehara N, Kobayashi M, Takemura M. Effects of systemic bicuculline or morphine on formalin-evoked pain-related behaviour and c-Fos expression in trigeminal nuclei after formalin injection into the lip or tongue in rats. Exp Brain Res. 2009;196:229-37.

21. lyengar S, Ossipov MH, Johnson KW. The role of CGRP in peripheral and central pain mechanisms including migraine. Pain. 2017;158:543-59.

22. Nakamura K, Watakabe A, Hioki H, Fujiyama F, Tanaka Y, Yamamori T, Kaneko T. Transiently increased colocalization of vesicular glutamate transporters 1 and 2 at single axon terminals during postnatal development of mouse neocortex: a quantitative analysis with correlation coefficient. Eur J Neurosci. 2007;26:3054-67.

23. Paxinos $G$, Watson $C$. The rat brain in stereotaxic coordinates. 6th ed. Amsterdam: Elsevier Academic Press; 2007.

24. Paxinos G. The Rat Nervous System. 3rd ed. Amsterdam: Elsevier Academic Press; 2004. p. 817-51.

25. Gu Y, Chen Y, Ye L. Electron microscopical demonstration of horseradish peroxidase by use of tetramethylbenzidine as chromogen and sodium 
tungstate as stabilizer (TMB-ST method): a tracing method with high sensitivity and well preserved ultrastructural tissue. J Neurosci Methods. 1992;42:1-10.

26. Hylden $J L$, Nahin RL, Traub RJ, Dubner R. Expansion of receptive fields of spinal lamina I projection neurons in rats with unilateral adjuvantinduced inflammation: the contribution of dorsal horn mechanisms. Pain. 1989;37:229-43.

27. Iwata K, Kenshalo DR Jr, Dubner R, Nahin RL. Diencephalic projections from the superficial and deep laminae of the medullary dorsal horn in the rat. J Comp Neurol. 1992;321:404-20.

28. Krout KE, Belzer RE, Loewy AD. Brainstem projections to midline and intralaminar thalamic nuclei of the rat. J Comp Neurol. 2002;448:53-101.

29. Kemplay S, Webster KE. A quantitative study of the projections of the gracile, cuneate and trigeminal nuclei and of the medullary reticular formation to the thalamus in the rat. Neuroscience. 1989;32:153-67.

30. Aicher SA, Hermes SM, Hegarty DM. Corneal afferents differentially target thalamic- and parabrachial-projecting neurons in spinal trigeminal nucleus caudalis. Neuroscience. 2013;232:182-93.

31. Guy N, Chalus M, Dallel R, Voisin DL. Both oral and caudal parts of the spinal trigeminal nucleus project to the somatosensory thalamus in the rat. Eur J Neurosci. 2005;21:741-54.

32. Erzurumlu RS, Bates CA, Killackey HP. Differential organization of thalamic projection cells in the brain stem trigeminal complex of the rat. Brain Res. 1980;198:427-33.

33. Cechetto DF, Standaert DG, Saper CB. Spinal and trigeminal dorsal horn projections to the parabrachial nucleus in the rat. J Comp Neurol. 1985; 240:153-60.

34. Slugg RM, Light AR. Spinal cord and trigeminal projections to the pontine parabrachial region in the rat as demonstrated with Phaseolus vulgaris leucoagglutinin. J Comp Neurol. 1994;339:49-61.

35. Feil $\mathrm{K}$, Herbert $\mathrm{H}$. Topographic organization of spinal and trigeminal somatosensory pathways to the rat parabrachial and Kolliker-fuse nuclei. J Comp Neurol. 1995;353:506-28.

36. Standaert DG, Watson SJ, Houghten RA, Saper CB. Opioid peptide immunoreactivity in spinal and trigeminal dorsal horn neurons projecting to the parabrachial nucleus in the rat. J Neurosci. 1986;6:1220-6.

37. Dallel R, Ricard O, Raboisson P. Organization of parabrachial projections from the spinal trigeminal nucleus oralis: an anterograde tracing study in the rat. J Comp Neurol. 2004;470:181-91.

38. Allen GV, Barbrick B, Esser MJ. Trigeminal-parabrachial connections: possible pathway for nociception-induced cardiovascular reflex responses. Brain Res. 1996;715:125-35.

39. Dubner R, Bennett GJ. Spinal and trigeminal mechanisms of nociception. Annu Rev Neurosci. 1983;6:381-418.

40. Bereiter DA, Hirata H, Hu JW. Trigeminal subnucleus caudalis: beyond homologies with the spinal dorsal horn. Pain. 2000;88:221-4.

41. Woda A. Pain in the trigeminal system: from orofacial nociception to neural network modeling. J Dent Res. 2003;82:764-8.

42. Priestley JV, Somogyi P, Cuello AC. Immunocytochemical localization of substance $P$ in the spinal trigeminal nucleus of the rat: a light and electron microscopic study. J Comp Neurol. 1982;211:31-49.

43. Pearson JC, Jennes L. Localization of serotonin- and substance P-like immunofluorescence in the caudal spinal trigeminal nucleus of the rat. Neurosci Lett. 1988;88:151-6.

44. Li YQ, Substance P. Receptor-like immunoreactive neurons in the caudal spinal trigeminal nucleus send axons to the gelatinosus thalamic nucleus in the rat. J Hirnforsch. 1999;39:277-82.

45. Li JL, Ding YQ, Xiong KH, Li JS, Shigemoto R, Mizuno N. Substance P receptor (NK1)-immunoreactive neurons projecting to the periaqueductal gray: distribution in the spinal trigeminal nucleus and the spinal cord of the rat. Neurosci Res. 1998;30:219-25.

46. Willis WD, Westlund KN. Neuroanatomy of the pain system and of the pathways that modulate pain. J Clin Neurophysiol. 1997;14:2-31.

47. Willis WD Jr, Zhang X, Honda CN, Giesler GJ Jr. Projections from the marginal zone and deep dorsal horn to the ventrobasal nuclei of the primate thalamus. Pain. 2001;92:267-76.

48. Graziano A, Jones EG. Widespread thalamic terminations of fibers arising in the superficial medullary dorsal horn of monkeys and their relation to calbindin immunoreactivity. J Neurosci. 2004;24:248-56.

49. Sugimoto T, Hara T, Shirai H, Abe T, Ichikawa H, Sato T. C-fos induction in the subnucleus caudalis following noxious mechanical stimulation of the oral mucous membrane. Exp Neurol. 1994;129:251-6.
50. Carstens E, Saxe I, Ralph R. Brainstem neurons expressing c-Fos immunoreactivity following irritant chemical stimulation of the rat's tongue. Neuroscience. 1995;69:939-53.

51. Hathaway CB, Hu JW, Bereiter DA. Distribution of Fos-like immunoreactivity in the caudal brainstem of the rat following noxious chemical stimulation of the temporomandibular joint. J Comp Neurol. 1995;356:444-56.

52. Martinez S, Belmonte C. C-Fos expression in trigeminal nucleus neurons after chemical irritation of the cornea: reduction by selective blockade of nociceptor chemosensitivity. Exp Brain Res. 1996;109:56-62.

53. Morgan Il, Curran T. Stimulus-transcription coupling in the nervous system: involvement of the inducible proto-oncogenes fos and jun. Annu Rev Neurosci. 1991;14:421-51.

54. Adams JC. Sound stimulation induces Fos-related antigens in cells with common morphological properties throughout the auditory brainstem. J Comp Neurol. 1995;361:645-68.

55. Li JL, Kaneko T, Nomura S, Li YQ, Mizuno N. Association of serotonin-like immunoreactive axons with nociceptive projection neurons in the caudal spinal trigeminal nucleus of the rat. J Comp Neurol. 1997;384:127-41.

56. Fujisawa N, Terayama R, Yamaguchi D, Omura S, Yamashiro T, Sugimoto T. Fos protein-like immunoreactive neurons induced by electrical stimulation in the trigeminal sensory nuclear complex of rats with chronically injured peripheral nerve. Exp Brain Res. 2012;219:191-201.

57. Lu SM, Lin RC. Thalamic afferents of the rat barrel cortex: a light- and electron-microscopic study using Phaseolus vulgaris leucoagglutinin as an anterograde tracer. Somatosens Mot Res. 1993;10:1-16.

58. Diamond ME, Armstrong-James M, Ebner FF. Somatic sensory responses in the rostral sector of the posterior group (POm) and in the ventral posterior medial nucleus (VPM) of the rat thalamus. J Comp Neurol. 1992;318:462-76.

59. Rausell $E$, Jones EG. Chemically distinct compartments of the thalamic VPM nucleus in monkeys relay principal and spinal trigeminal pathways to different layers of the somatosensory cortex. J Neurosci. 1991;11:226-37.

60. Hartings JA, Simons DJ. Inhibition suppresses transmission of tonic vibrissaevoked activity in the rat ventrobasal thalamus. J Neurosci. 2000;20:RC100.

61. Norgren $\mathrm{R}$, Leonard CM. Taste pathways in rat brainstem. Science. 1971;173:1136-9.

62. Ogawa H, Hayama T, Ito S. Response properties of the parabrachiothalamic taste and mechanoreceptive neurons in rats. Exp Brain Res. 1987:68:449-57.

63. Travers JB, Travers SP, Norgren R. Gustatory neural processing in the hindbrain. Annu Rev Neurosci. 1987;10:595-632.

64. Chamberlin NL, Saper CB. Topographic organization of cardiovascular responses to electrical and glutamate microstimulation of the parabrachial nucleus in the rat. J Comp Neurol. 1992;326:245-62.

65. Krukoff TL, Harris KH, Jhamandas JH. Efferent projections from the parabrachial nucleus demonstrated with the anterograde tracer Phaseolus vulgaris leucoagglutinin. Brain Res Bull. 1993;30:163-72.

66. Jhamandas JH, Petrov T, Harris KH, Vu T, Krukoff TL. Parabrachial nucleus projection to the amygdala in the rat: electrophysiological and anatomical observations. Brain Res Bull. 1996;39:115-26.

67. Fulwiler CE, Saper CB. Subnuclear organization of the efferent connections of the parabrachial nucleus in the rat. Brain Res. 1984;319: 229-59.

68. Bester H, Besson JM, Bernard JF. Organization of efferent projections from the parabrachial area to the hypothalamus: a Phaseolus vulgarisleucoagglutinin study in the rat. J Comp Neurol. 1997;383:245-81.

69. Balaban CD, Thayer JF. Neurological bases for balance-anxiety links. J Anxiety Disord. 2001:15:53-79.

70. Petrovich GD, Swanson LW. Projections from the lateral part of the central amygdalar nucleus to the postulated fear conditioning circuit. Brain Res. 1997;763:247-54.

71. Tassoni G, Bucherelli C, Bures J. Postacquisition injection of tetrodotoxin into the parabrachial nuclei elicits partial disruption of passive avoidance reaction in rats. Behav Neural Biol. 1992;57:116-23.

72. Bernard JF, Bester H, Besson JM. Involvement of the spino-parabrachio -amygdaloid and -hypothalamic pathways in the autonomic and affective emotional aspects of pain. Prog Brain Res. 1996;107:243-55.

73. Bester H, Chapman V, Besson JM, Bernard JF. Physiological properties of the lamina I spinoparabrachial neurons in the rat. J Neurophysiol. 2000; 83:2239-59. 
74. Ma W, Peschanski M. Spinal and trigeminal projections to the parabrachial nucleus in the rat: electron-microscopic evidence of a spino-pontoamygdalian somatosensory pathway. Somatosens Res. 1988;5:247-57.

75. Takamori S, Rhee JS, Rosenmund C, Jahn R. Identification of a vesicular glutamate transporter that defines a glutamatergic phenotype in neurons. Nature. 2000;407:189-94.

76. Takamori S, Rhee JS, Rosenmund C, Jahn R. Identification of differentiationassociated brain-specific phosphate transporter as a second vesicular glutamate transporter (VGLUT2). J Neurosci. 2001;21:RC182.

77. Takamori S. VGLUTS: 'exciting' times for glutamatergic research? Neurosci Res. 2006;55:343-51.

78. Kaneko T, Fujiyama F, Hioki H. Immunohistochemical localization of candidates for vesicular glutamate transporters in the rat brain. J Comp Neurol. 2002;444:39-62.

79. Li H, Li YQ. Collateral projection of substance P receptor expressing neurons in the medullary dorsal horn to bilateral parabrachial nuclei of the rat. Brain Res Bull. 2000;53:163-9.

80. Cadden SW, Orchardson R. The neural mechanisms of oral and facial pain. Dent Update. 2001;28:359-67.

81. Sessle BJ. The neurobiology of facial and dental pain: present knowledge, future directions. J Dent Res. 1987;66:962-81.

82. Kuzawinska O, Lis K, Cessak G, Mirowska-Guzel D, Balkowiec-Iskra E. Targeting of calcitonin gene-related peptide action as a new strategy for migraine treatment. Neurol Neurochir Pol. 2016;50:463-7.

83. Jacquin MF, Golden J, Panneton WM. Structure and function of barrel 'precursor' cells in trigeminal nucleus principalis. Brain Res. 1988;471:309-14.

84. Veinante $P$, Deschenes $M$. Single- and multi-whisker channels in the ascending projections from the principal trigeminal nucleus in the rat. J Neurosci. 1999;19:5085-95.

85. Kozlovskii VL, Mosin AE, Ivakina LV. The effect of calcium channel blockers on anxiety evoked by amputation of the vibrissae in rats. Eksp Klin Farmakol. 1997;60:10-2.

\section{Submit your next manuscript to BioMed Central and we will help you at every step:}

- We accept pre-submission inquiries

- Our selector tool helps you to find the most relevant journal

- We provide round the clock customer support

- Convenient online submission

- Thorough peer review

- Inclusion in PubMed and all major indexing services

- Maximum visibility for your research

Submit your manuscript at www.biomedcentral.com/submit 